NBER WORKING PAPER SERIES

THE AGGREGATE MATCHING FUNCTION

Olivier Jean Blanchard

Peter Diamond

Working Paper No. 3175

NATIONAL BUREAU OF ECONOMIC RESEARCH

1050 Massachusetts Avenue

Cambridge, MA 02138

November 1989

This paper is part of an alternative presentation of the material in our 1989 paper. In addition, we report on additional findings on the aggregate matching function and start looking, theoretically and empirically, at wage determination and the relation between the Phillips and Beveridge Curves. We thank the NSF for financial assistance and DRI for access to their data base. We thank Hugh Courtney and Juan Jimeno for excellent research assistance, John Abowd and Arnold Zellner for their gross flow data, Kathy Abraham for help with the vacancy data, George Akerlof, Nils Gottfries, Bob Hall, Jerry Hausman, Larry Katz, Chris Pissarides, Bob Solow, Larry Summers, and Janet Yellen for comments. This paper is part of NBER's research program in Economic Fluctuations. Any opinions expressed are those of the authors not those of the National Bureau of Economic Research. 
NBER Working Paper \#3175

November 1989

\section{THE AGGREGATE MATCHING FUNCTION}

\section{ABSTRACT}

We present a picture of the labor market, one with large flows of jobs and workers, and matching. We develop a consistent approach to the interaction among those flows and the stocks of unemployed workers and vacant jobs, and to the determination of wages. We estimate the matching function, using both aggregate data and data from manufacturing and find evidence of a stable matching process in the data. We examine the joint movements in unemployment, vacancies and wages - the Beveridge and Phillips curve relations- in the light of our model. We conclude that aggregate activity shocks rather than reallocation shocks dominate the movement of unemployment.

\author{
Olivier Jean Blanchard \\ MIT \\ Department of Economics \\ 50 Memorial Drive \\ Cambridge, MA 02139
}

Peter Diamond

MIT

Department of Economics

50 Memorial Drive

Cambridge, MA 02139 
Bob Solow has written: "Any time seems to be the right time for reflections on the Phillips curve"(1976). And since his 1960 paper with Paul Samuelson, he has reflected many times.

Their joint paper is widely known for having drawn the first American Phillips curve. In fact, having drawn it, Samulson and Solow quickly put distance between themselves and the curve. Having duly noted the empirical fit, they pointed out that the Phillips curve had disappeared during the Depression, and suggested that persistent high unemployment could well reduce labor mobility and increase structural unemployment. They expressed skepticism as to the long run trade off, writing. "it would be wrong, though, to think that our figure 2 menu that relates obtainable price and unemployment behavior will maintain the same shape in the longer run". They argued that imperfect competition was the right setting for studying cost push inflation. They emphasized that many factors were at work in the labor market including labor reallocation, labor mobility, collective bargaining; thus no simple or single explanation was likely to account for the relation between wages and unemployment.

Many of Solow's later papers were further explorations of those early themes. His 1964 Wicksell lectures developed the view of the labor market as a market with consiant reallocation of labor and addressed the question of how much of unemployment was due to low demand and how much to structural factors. To do so, he brought to the scene boch the Phillips curve and the Beveridge curve, a strategy we shall pursue below. In his 1969 Manchester lectures, Solow noted that, with mulciple equilibria, "the economy 
might be jolted out of an underemployment equilibrium". Solow's more recent work has returned to the relation between collective bargaining and unemployment. In a field where fashion rules, the papers read as well or better today than when they were written. This is because they combine four traits -an eye on the facts, an eclectic view of the large number of complications wich are relevant for the short run behavior of the economy, an awareness of the implications of neoclassical theory, and an unwillingness to give neoclassical implications more than their due.

We are both students of Solow, one of Solow the growth theorist, the other of solow the macroeconomist. One of us came to study labor markets as a result of the internal logic of a research program based on the idea that decentralized markets work very differently from models designed for centralized markets. The other was motivated by the recent European experience, and the potential role of collective bargaining in explaining the persistence of unemployment. Our collaboration on this paper was begun two years ago to take up two challenges. The first was whether, as a team, we could emulate the back and forth between theory and empirical work which solow does so well alone. The second was to find a framework for thinking about collective bargaining in labor markets characterized by large flows and constant reallocation of labor across jobs. We are not yet where we want to go. Put more bluntly, we have captured the large flows but not yet introduced collective bargaining. Nevertheless, we think we have made progress; this paper is a progress report.

Our basic thene is that the labor market is a market with large flows of workers, and simultaneously large rates of job creation and destruction. Evidence on the large flows of workers in the US comes from the monthly household survey. While the raw data on gross flows are biased upwards, the numbers remain very high when the bias is 
removed. The series as adjusted by Abowd and zellner imply that, each month, roughly 78 of the labor force moves in or out of employment. While this could be consistent with workers reallocating themselves across a given set of jobs, recent evidence by Davis and Haltiwanger shows this not to be the case. Looking at a large number of establishments, they compute a measure of job turnover, defined as the sum of employment increases in new or expanding establishments, and employment decreases in shrinking or dying establishments. They find that in manufacturing, over the period 1979-1983, a period of shrinking employment, job turnover was of the order of 108 per quarter.

Thus, at any point in time, many firms are looking for workers, many workers are looking for jobs. How many hires result from a given number of vacancies and workers depends on the geography of job destruction and job creation, on skill differences between workers and jobs, on how eagerly workers and firms are looking for each other and so on. In the same spirit as solow used an aggregate production function, bypassing complex issues of aggregation to get to the basic issues of growth and productivity, we start our paper by estimating an aggregate matching function, giving the flow of hires as a function of the stocks of vacancies and unemployment ${ }^{2}$. We estimate this function for the Us for the period 1968-1981-the only period for which the required data are available. We find a stable, Cobb-Douglas matching function with a declining time trend, equal weight on vacancies and unemployment and constant or mildly increasing returns to scale. Thus very much like the production function, the abstraction turns out to be both conceptually helpful and empirically relevant. We

2 Pissarides (1986) has estimated a matching function for the UK. 
then make two attempts at estimating disaggregated matching functions. Both are hampered by problems of data quality, but both turn out nevertheless to give interesting results. The first looks at matching in manufacturing. For a brief period of time, 1969-1973, the BLS collected monthly vacancy statistics for manufacturing; this allows estimation of a matching function for that period. Much like the aggrregate matching function, the matching function for manufacturing exhibits roughly equal weights on vacancies and unemployment, and mildly increasing returns. The second attempt is motivated by the fact that close to 408 of new hires are of people officially classified as "out of the labor force". Thus, we look separately at hires from the unemployment pool and hires from "out of the labor force". The two hires series are available separately, and BLS provides a series for workers classified as "out of the labor force but wanting a job", which can be taken as a proxy for the relevant pool of people "out of the labor force". The data show sharp differences between the two groups, differences which are consistent with differences in either the variation of search intensity through time, and in the way employers view and choose between the two groups.

Using the aggregate matching function, we build a simple model of the labor market which focuses on the flows in Sections 2 and 3 . It has two basic ingredients. The first is that it takes time to reallocate, to match workers and jobs; this is captured by the matching function. The second is the assumption that there is unceasing job destruction and job creation, continual layoffs and posting of vacancies. Wages are assumed to divide the surplus from a match jetween a worker and a job; a natural assumption is that of Nash bargaining. Thus, there is no tight connection between wages and employment. At any point in time, a change in the wage -coming say from changes in relative bargaining power - has no effect on employment. Only over time, would the wage 
affect the profitability of jobs, the supply of jobs and the level of employment. This lack of an allocational role for the wage in the short run is surely too strong; however it is likely to be a better approximation to the role of wages than the other extreme, that employment depends on the wage even in the very short run.

The model makes clear predictions about how different shocks affect unemployment, vacancies and wages. Contractions in aggregate activity increase unemployment and decrease vacancies, both putting downward pressure on wages. In contrast, periods of intense reallocation increase both unemployment and vacancies but may be associated with litcle or no pressure on wages. This suggests that an empirical examination of the joint behavior of the Philips and Beveridge curves through the lenses of the model can tell us a lot about the sources of the shocks affecting an economy, Put too strongly, the model allows us to look, in an integrated fashion, at the Beveridge curve and the Phillips curve. The statement is too strong because, at this stage, we stay away from formalizing nominal rigidities, although we suggest how they can be naturaliy introduced. We have started following this lead and, in Section 4, report on some of our progress for the postwar us. We have worked hard on the Beveridge curve, but just peeked at the Philips curve. Our conclusions at this stage are that, in the post war US, major movements in unemployment have been mostly the result of changes in aggregate activity, not of changes in the intensity or the effectiveness of the reallocation process. Reallocation changes appear however to have played a more important role at lower frequencies. These conclusions probably sound more authoricative than is warranted: our preliminary examination of the Phillips curve yields a number of puzzles which we discuss and will have to resolve. 
1. The Aggregate Matching Function

If the right picture of the labor market has constant churning of workers and jobs, the matching process is at the center of the picture. Thinking in terms of an aggregate matching function is an attractive way of thinking about the dynamics of hiring and employment. It is more appealirg than postulating a stock adjustment equation for employment. It is also more appealing than equating employment with labor demand, another standard alternative. If the speed of filling vacancies did not depend on labor market conditions, we would find no role for unemploynent in the matching process. As we shall see below, this is not the case.

Estimation of an aggregate matching function can also shed light on the role of different classes of workers (short term-long term, skilled-unskilled, in or out of the labor force) in the matching process. Micro studies are no substitute for that information. For example, cross section results on the importance of unemployment compensation for the likelihood of finding a job do not translate directy into implications for aggregate unemployment since less availability by some workers will raise the probability of job finding by others.

Why might even a believer in the importance of labor market flows object to giving a central role to the matching function? We have heard two objections. The first is that the concept of a vacancy is much vaguer than the concept of an unemployed worker. making it unlikely that vacancies are a useful concept for organizing empirical work. We feel that the concepts of unemployed workers and vacancies both represent an attempt to substitute a scalar variable (the number available) for a schedule of availability as a function of the attractiveness of opportunities. In both cases, whether those scalar variables are useful or not must be judged in large part by the degree of 
empirical success when they are used. And, as we shall see, both series appear to be successful in that regard. A separate but related issue is that there does not exist a vacancy series for the US -or any other country we know of - constructed with the care and coverage of the unemployment series. In the US, the substitute we have is the Conference Board's Help Wanted Index which has been adjusted by Katharine Abraham to better approximate vacancies. Again, the adequacy of that proxy must be judged in the end by how it performs in estimation. For 1969 to 1973, we do have a vacancy series for manufacturing. We also report estimates using that data.

The second objection is of a different nature. It is that vacancies are only an intermediate variable, and that one must explain how new vacancies evolve over time. It is indeed true that the matching function is only part of the story; any complete story must account for job creation and job destruction and their determinants. It is nevertheless an essential part of the story. Again, the parallel with the aggregate production function is an obvious one.

In thinking about matches, we envision each worker and firm as engaged in a time consuming (stochastic) process of waiting for and looking for an appropriate match. We formalize the matching process by an aggregate function which gives new hires, h, as a function of unemployment and vacancies:

(1) $h=\alpha m(U, V)$

where $\alpha$ is a scale parameter, and $m_{U}, m_{V} \geq 0, m(0, V)-m(U, 0)=0$.

This matching function recognizes that the large labor market flows in the US generate delays in the finding of both jobs and workers. From a macroeconomic point of view, i.e., leaving aside the heterogeneity of individual workers or vacancies, the process is extremely efficient: the average duration of unemployment rarely exceeds 3 months, 
the average duration of vacancies does not exceed a month. But the process is simply not infinitely efficient and the speeds of job finding and job filling vary noticeably over the cycle. Changes in the parameter $\alpha$ are intended to capture changes in geographic or skill distributions of jobs and workers, -what is sometimes called mismatch- as well as differences in search and match acceptance behavior. In estimation below, $\alpha$ is formalized as a deterministic time trend.

Given the size of the flows relative to the stocks, it is essential to estimate the matching function using the highest frequency data available, which here means monthly data. None of the series needed to estimate the matching function is directly available and we construct them as follows (Specific sources and details of construction are given in our BPEA paper).

We construct new hires as the sum of the flows into employment from unemployment and from out of the labor force (taken from the CPS gross flows data as adjusted by Abowd and Zellner (1985) and deseasonalized using frequency domain filcering), to which we add the flow from employment to employment (estimated as 0.4 times the manufacturing quit rate times employment; for a discussion of employment to employment quits see Akerlof, Rose, and Yellen (1988)), and from which we subtract the flow of workers who are recalled rather than newly hired (estimated as 1.5 times manufacturing recalls). The resulting new hires series is plotted in figure 1 , along with our measures of unemployment and vacancies described below. One obvious characteristic of the series is its large high frequency movements, which in turn come from the movements in the CPS gross flow series. We believe that these movements come largely from sampling and classification error: the Abowd-Zeliner adjustment removes the mean error but not its random component. If this is the case, the series can still be used as a left hand side variable in a regression. 


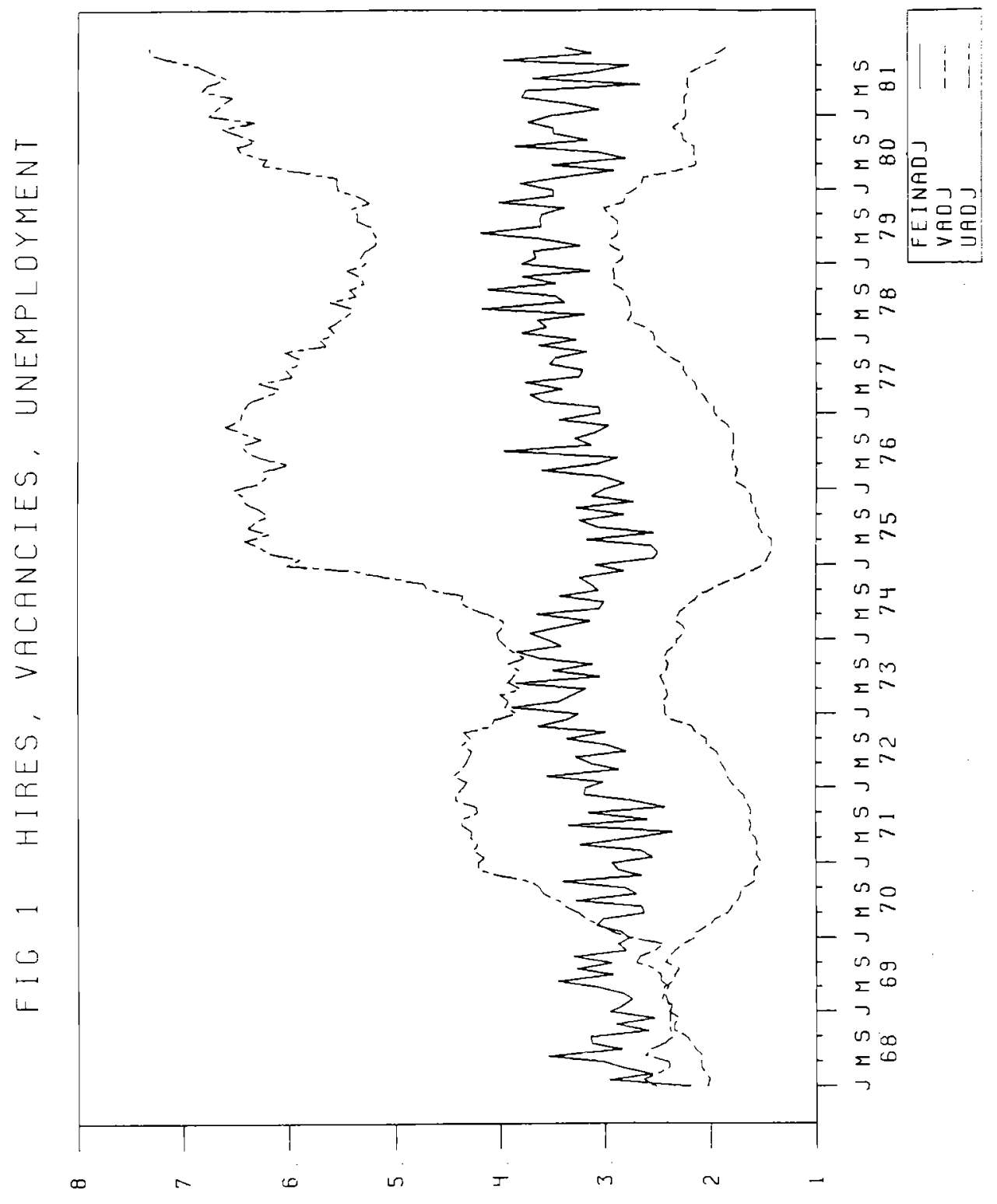


The composition of the gross flow into employment shows clearly that the relevant pool of workers includes more than just the unemployed. We estimate that on average 458 of new hires come from unemployment, 408 from out of the labor force and $15 \%$ directly from employment. By using unemployment in most of what follows, we implicitly assume that the relevant pool is proportional to the pool of unemployed workers. We take the pool of unemployment to equal to the total number of unemployed workers minus those workers classified as "job losers on layoff", workers who consider themselves as having a job. We explore alternative definitions of the pool below.

For the aggregate vacancy series we use the help-wanted series constructed by the Conference Board, and adjust it following Abraham (1983, 1987). We adjust the level of the series so that its mean is similar to the mean reported vacancy rate for the periods of time for which such a rate is available (Abraham 1983, table 3). This yields a mean vacancy rate of 2.28 for the period $68: 1$ to $81: 12$, the period for which all the data we use are available. The mean of the unemployment rate as defined is 4.88 for this period.

\section{The aggregate matching function: basic specifications}

Our basic specification gives new hires as a Cobb Douglas function of vacancies and unemployment, with all variables defined as above:

$\ln \left(H_{t}\right)-a+b \operatorname{time}+c \ln \left(V_{t-1}\right)+d \ln \left(\mathrm{C}_{t-1}\right)+\epsilon_{t}$

There is no clean way of handing timing. First, reality is in continuous time and we have discrete time data. With the mean duration of vacancies under a month, a literal interpretation of an equation such as the one above would make no sense as the flow of new hires during the month exceeds the total number of vacancies at a point in 
Independent variables : coefficients on :

constant $\underset{\left(\times 10^{-2}\right)}{\operatorname{time}} \ln (\mathrm{V}(-1)) \ln (\mathrm{U}(-1))$ RTS elasticity $\rho \quad$ DW $\quad \mathrm{R}^{2}$

Dependent variable

$\ln (H)$

\begin{tabular}{|c|c|c|c|c|c|c|c|c|c|}
\hline (1) (OLS) & $\begin{array}{c}.52 \\
(7.5)\end{array}$ & $\begin{array}{c}. .15 \\
(-2.4)\end{array}$ & $\begin{array}{c}.54 \\
(6.9)\end{array}$ & $\begin{array}{c}.35 \\
(3.9)\end{array}$ & .9 & $1.0 *$ & $.0 \star$ & 2.4 & .47 \\
\hline (2) (OLS) & $\begin{array}{c}.49 \\
(16.0)\end{array}$ & $\begin{array}{c}-.19 \\
(-11.0)\end{array}$ & $\begin{array}{c}.59 \\
(27.5)\end{array}$ & $(18.9)$ & $1.0 *$ & $1.0 \star$ & $.0 \star$ & 2.4 & .47 \\
\hline (3) (IV) & $\begin{array}{c}.36 \\
(2.1)\end{array}$ & $\begin{array}{c}-.33 \\
(-1.9)\end{array}$ & $\begin{array}{c}.75 \\
(4.0)\end{array}$ & $\begin{array}{c}.60 \\
(2.4)\end{array}$ & 1.35 & $1.0 *$ & $.0 *$ & 2.3 & .43 \\
\hline (4) (NLS) & $\left(12^{.48}\right)$ & $\begin{array}{c}-.20 \\
(-10.0)\end{array}$ & $\begin{array}{c}.52 \\
(7.2)\end{array}$ & .48 & $1.0 \star$ & $\begin{array}{c}.74 \\
(3.7)\end{array}$ & $.0 *$ & 2.4 & .48 \\
\hline (5) (ARl) & $\begin{array}{c}.52 \\
(9.2)\end{array}$ & $\begin{array}{l}-.15 \\
(-3.0)\end{array}$ & $\begin{array}{c}.54 \\
(16.5)\end{array}$ & .46 & $1.0 *$ & $1.0 *$ & $\begin{array}{l}-.2 \\
(-2.8)\end{array}$ & $(2.0)$ & .49 \\
\hline (6) (IV) & $\begin{array}{c}.45 \\
(2.7)\end{array}$ & $\begin{array}{c}-.20 \\
(-1.2)\end{array}$ & $\begin{array}{c}\ln (\mathrm{V}) \\
.62 \\
(4.3)\end{array}$ & $\begin{array}{r}\ln (\mathrm{U}) \\
.42 \\
(2.3)\end{array}$ & 1.04 & $1.0 \star$ & $.0 *$ & 2.4 & .41 \\
\hline
\end{tabular}

Period of estimation: $68: 2$ to $81: 12$

$t$ statistics in parentheses

Instruments for (3): $\ln (I P)$, lagged two to four times; IP : industrial production Instruments for (6): $\ln (\mathrm{V}), \ln (\mathrm{U})$ lagged one to three times RTS denotes the estimated degree of returns to scale.

Table 2. The matching function in manufacturing

Independent variables: coefficients on:

$$
\text { constant } \ln (\operatorname{VM}(-1)) \ln (\mathrm{U}(-1)) \text { RTS } \rho \text { DW } \mathrm{R}^{2}
$$

Dependent variable:

$\ln (\mathrm{H} M)$
(1) (OLS)
$\begin{array}{cc}2.04 & .71 \\ (6.1) & (14.7)\end{array}$
67
$\begin{array}{llll}1.37 & .37 & 2.03 \quad .92\end{array}$
(2) (IV)

$\begin{array}{lcccccc}1.92 & .72 & .71 & 1.43 & .37 & 2.01 & .92 \\ (5.5) & (14.6) & (7.2) & & (.75) & & \end{array}$


time. Insofar as the discrete time specification works empirically, it relies on the smoothness of the continuous time pattern of vacancies. Second, while one would want to regress new hires during the month on the two stocks at the same time of the month, the data do not come in that form. Some of our daca are point in time, some integrals of stocks (for vacancies) or flows (for hires) over time. Our specification is a compromise. We alsopresent the results of estimation with current values of $V$ and $U$, instrumented by their lagged values.

The results are presented in table 1. The first regression estimates the equation. as specified above. The second imposes constant returns, i.e., c+d-1. Both use oLs. However, if the disturbance term to the hiring function includes a serially correlated component, OLS estimation may lead to a downward bias in the estimated coefficients on unemployment and vacancies: a positive disturbance to hiring leads, ceteris paribus, to a decrease in unemployment and vacancies. Thus, the third regression estimates the equation using industrial production, lagged two to five times as an instrument: to the extent that firms can vary hours to compensate for disturbances in hiring, industrial production is likely to be affected less by disturbances to the matching function than are either unemployment or vacancies. Thus, the use of industrial production surely removes some, although perhaps not all, of the bias. The fourth regression allows for the elasticity of substitution between $V$ and $U$ to differ from one, by estimating a CES instead of a cobb Douglas specification. The fifth allows for first order serial correlation in the disturbance term. The sixth uses current values of $V$ and $U$, instrumented by their own lagged values. There is no evidence in favor of a more complex lag structure.

The results are clear cut and vary little over specifications. The hiring process is well described by a matching function with constant or mildly increasing returns to 
scale, unit elasticity of substitution, and relative weights of .6 and .4 on vacancies and unemployment. Returns to scale, are slightly less than 1.0 when estimated by OLS, but increase to 1.35 when lagged industrial production is used as an instrument (lagging industrial production further does not increase the estimated degree of returns to scale); the elasticity of substitution, when estimated, is equal to .74 , not significantly different from one. All specifications yield a trend decline in hires given unemployment and vacancies; using the first regression, the trend decline is of roughly 25 over the sample period. Using the third regression, the decline is roughly 40 over the sample period. With a specification that does not distinguish short from long run returns to scale, a greater estimate of returns to scale will tend to go with a more rapidly declining trend.

The result that both unemployment and vacancies matter implies that the rate of hiring is determined by both sides of the labor market, not only by demand. Put another way, the average duration of vacancies varies with the vacancy-unemployment ratio. The adjusted unemployment-vacancy ratio varies between 5.0 and 0.9 over this period. Using regression (2), we estimate that the average duration of vacancies is equal to 2 weeks, when the ratio is equal to 5 ; when the ratio equals.9, the average duration of vacancies increases to 4 weeks ${ }^{3}$. Just as with unemployment, the average duration also hides differences in durations across vacancies; a 1964 Rochester study (Myers and Creamer 1967) found that, while the median duration was 4 weeks, more than

3 One can obviously compute the average duration of unemployment as well. The two corresponding numbers are 2.3 and .8 months. But as unemployment proxies for a larger pool of workers, these numbers are misleading. 
408 of vacancies had durations in excess of 6 weeks and 208 had durations in excess of 12 weeks $^{4}$.

The presence of a negative trend during the sample suggests a potential proximate source for the shift in the Beveridge curve, an issue to which we shall briefly return. Where this trend comes from however, we do not investigate further.

Recent theoretical developments have argued for the plausibility and potential importance for macroeconomics of increasing returns in matching ${ }^{5}$. Plausibility of increasing returns comes from the idea that active, thick, markets may lead to easier matching. The evidence suggests increasing, but not strongly increasing returns. Some downward bias may remain in this estimate, so that proponents of strongly increasing returns in the labor market may still have hope. Whatever the findings for the labor market, the different structure of the goods market leaves open the possibility of strong increasing returns to matching in the goods market.

Finally, we find no evidence of further non-linearities; we have explored the idea that, as unemployment increases, firms find workers as easily as they want, so that further increases in the unemployment rate, given vacancies, do not increase hiring. When we allow for additional non-linear terms in unemployment, or split the sample according to the value of the unemployment-vacancy ratio, we find no evidence of such an effect.

4 If the arrival rate of workers were constant, a median duration of vacancies of 4 weeks would imply a mean of 5.7 weeks ; 35 of vacancies would last more than 6 weeks. 5 See Diamond (1982). 


\section{The matching Eunction Eor manufacturing $1969-73$}

The necessity of constructing the time series used in the empirical work reported in table 1 makes it appealing to explore the matching function for manufacturing where the data needed were collected directly, if only briefly. New hires in manufacturing were collected on a monthly basis until 1981, and, in a four year experiment, from 1969 to 1973, data on vacancies at the end of the month were also collected. In table 2, we report some results using these alternative series. We use the same unemployment variable as earlier ${ }^{6}$. Since the time series is so short we omit the time trend. The first regression reports the results of OLS estimation, the second of IV estimation using lagged industrial production as an instrument. They give similar results, and results consistent with those of table 1 . Both vacancies and unemployment are significant, with approximately equal coefficients. This result, which again implies that manufacturing vacancies are harder to fill when unemployment is low, suggests that the image of manufacturing as a sector where workers queue for jobs, and firms just need to choose from a pool of waiting workers -as in efficiency wage models- is not quite correct. The average duration of a vacancy is lower for manufacturing than for the economy as a whole, roughly 10 days on average for the period we consider; but the

6 While there exists a series giving the number of unemployed who were last employed in manufacturing, it is clearly not appropriate. First it includes a large number of workers waiting to be recalled, and is indeed highly correlated with the series giving the number of workers on layoff waiting to be recalled. Second, a high proportion of new hires is of workers from outside of manufacturing. 
duration varies with market conditions. There is also evidence of increasing returns to scale.

The aggregate matching function: the relevant pool of workers

Our initial specification is based on the joint assumptions of an homogenous pool of workers, and that the relevant pool of workers is proportional to total unemployment minus layoff unemployment. Table 3 explores alternative definitions of the pool. allowing for different types of workers to be perfect substitutes up to a scalar level. That is, the regressions assume a relation of the form:

$$
\ln \left(\mathrm{H}_{\mathrm{t}}\right)=\mathrm{a}+\mathrm{b} \text { time }+c \ln \left(\mathrm{V}_{\mathrm{t}-1}\right)+(I-c) \ln \left(\mathrm{X}_{1 \tau-1}+\mathrm{dX}_{2 t-1}\right)+\epsilon_{t}
$$

where $x_{1}$ and $x_{2}$ denote two components of the pool, and are assumed to be perfect substitutes up to a scale parameter d. All regressions assume constant returns to scale.

None of the regressions yields precise estimates of the composition of the pool. The point estimates are nevertheless interesting.

The first regression examines the role of those unemployed classified as job losers on layoff, a group which was given a weight of zero in the basic specification. The point estimate of d is 98 , suggesting that some of those workers are also looking for jobs ${ }^{7}$. The second regression examines the role of those classified as out of the labor

7 Katz and Meyer (1987) find that workers not expecting to be recalled spend roughly twice as much time searching as those expecting to be recalled. The study however gives no direct information as to their respective reservation wages. 
Table 3. The aggregate matcting function

Alternative definitions of the pool

Independent variables : coefficients on:

$$
\text { constant } \underset{\left(\mathrm{x} 10^{-2}\right)}{\text { time }} \ln (\mathrm{V}(-1)) \mathrm{X}(-1) \quad \mathrm{X}(-2) \quad \mathrm{X}(-3) \text { DW } \mathrm{R}^{2}
$$

Dependent variable : $\ln (\mathrm{H})$

$\begin{array}{ccc}.48 & -.19 & .59 \\ (15.4) & (-7.1) & (23.1)\end{array}$

$\mathrm{U}$ Ulayoff

$1.0 * \quad .09$

(.2)

$2.4 \quad .47$

(2)

$\begin{array}{ccccccc}.25 & -.18 & .56 & 1.0 \star & .54 & \text { Wancjob } \\ (.4) & (-5.3) & (6.4) & & (.4) & 2.5 & .47\end{array}$

$\begin{array}{ccccc}.40 & -.17 & .57 & \text { U Out of LF } & \text { 1.0* } \\ (1.5) & (-4.3) & (9.5) & & (.3)\end{array}$

(4)

$\begin{array}{ccc}.48 & -.19 & .61 \\ (15.4) & (-5.0) & (17.7)\end{array}$

Ushort Ulong

1.0* 1.62

$2.4 \quad .47$

$$
(15.4)(-5.0)(17.7)
$$

$\begin{array}{lcc}.01 & -.18 & .58 \\ (.0) & (-5.2) & (6.4)\end{array}$

$\begin{array}{ccc}\text { Ushort Ulong Wantjob } \\ 1.0 * & 1.36 & 1.12\end{array}$

$2.5 \quad .47$

Period of estimation : $68: 2$ to $81: 12$ for zegressions (1), (3) and (4) $70: 2$ to $81: 12$ for regressions (2) and (5)

The specification is of the form:

$\ln (\mathrm{H})=\mathrm{a}+\mathrm{b}$ time $+\mathrm{c} \ln \left(\mathrm{V}(-1)+(1-\mathrm{c}) \ln \left(\mathrm{d}_{1} \mathrm{X}_{1}(-1)+\mathrm{d}_{2} \mathrm{X}_{2}(-1)+\mathrm{d}_{3} \mathrm{X}_{3}(-1)+\epsilon\right.\right.$ It is estimated by non linear least squares.

$t$ statistics in parentheses 
force but who indicate that, while they are not looking, they "want a job now"; this group is slightly larger on average than the pool of those classified as unemployed. The series is available only quarterly and needs to be interpolated; this probably reduces its usefulness in regressions. The estimated scale coefficient on this group is 548, confirming the evidence from the flow data that many in this group are indistinguishable from the unemployed. The next regression, which uses the series for all those out of the labor force yields essentially a zero scale parameter.

Regressions 4 and 5 consider the separate roles of the short term (less than 27 weeks) and long term unemployed. The first set of resulcs is surprising, finding a scale parameter on the long term unemployed in excess of unity. One tentative explanation is that long term unemployment is a better proxy for the pool of workers out of the labor force, and thus has a coefficient which is biased upwards. Regression 5 attempts to control for that by allowing for short term unemployment, long term unemployment and workers out of the labor force who want a job. Long term unemployment still has a scale coefficient which exceeds one. Thus the evidence, while statistically weak, does not suggest that short term and long term unemployed enter the matehing function differently ${ }^{8}$.

Hires from unemployment and out of the labor force

8 Katz (1986) finds no evidence of a declining job finding hazard once the recall hazard is taken into account. The evidence appears quite different in the UK, which has had a very different history of unemployment. See for example Jackman and Layard (1988), and Budd et al (1988). 
FIO 2 U, N ANO FLOWS FROM U RNO.N TO E

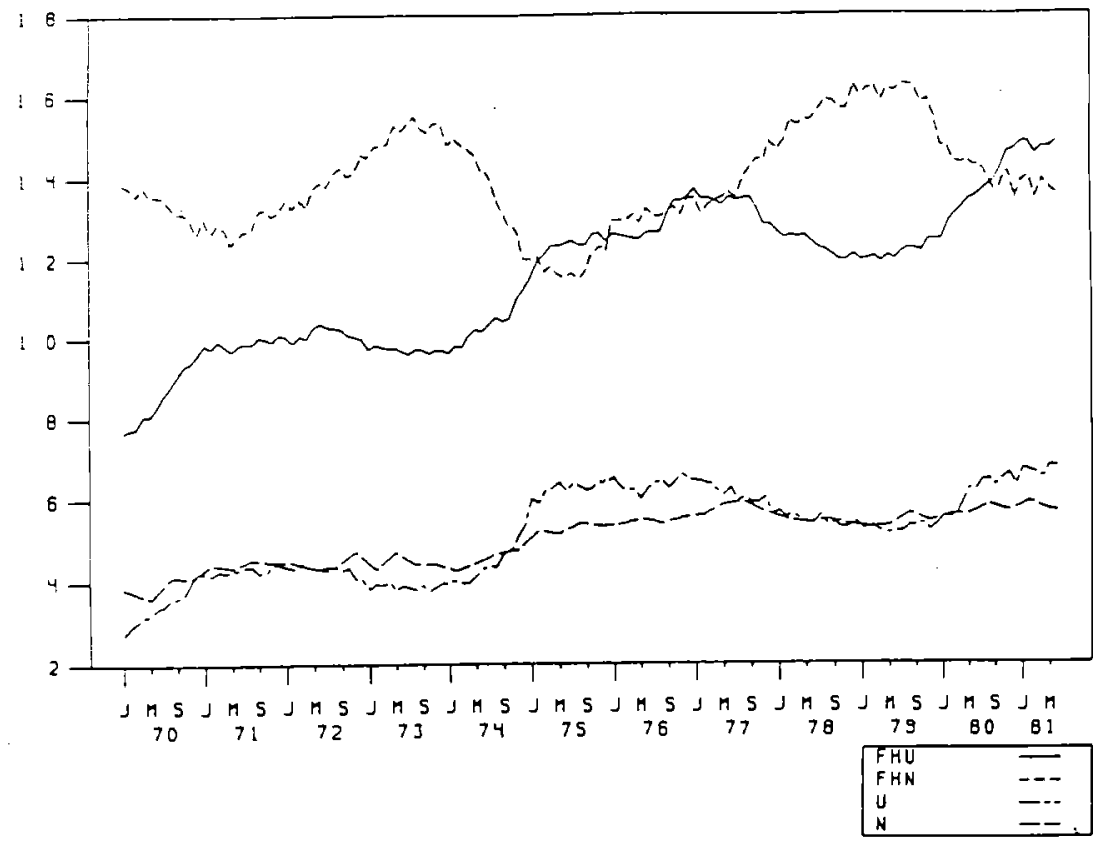

FIG 3 EXIT RATES FROM U. RND N TO E

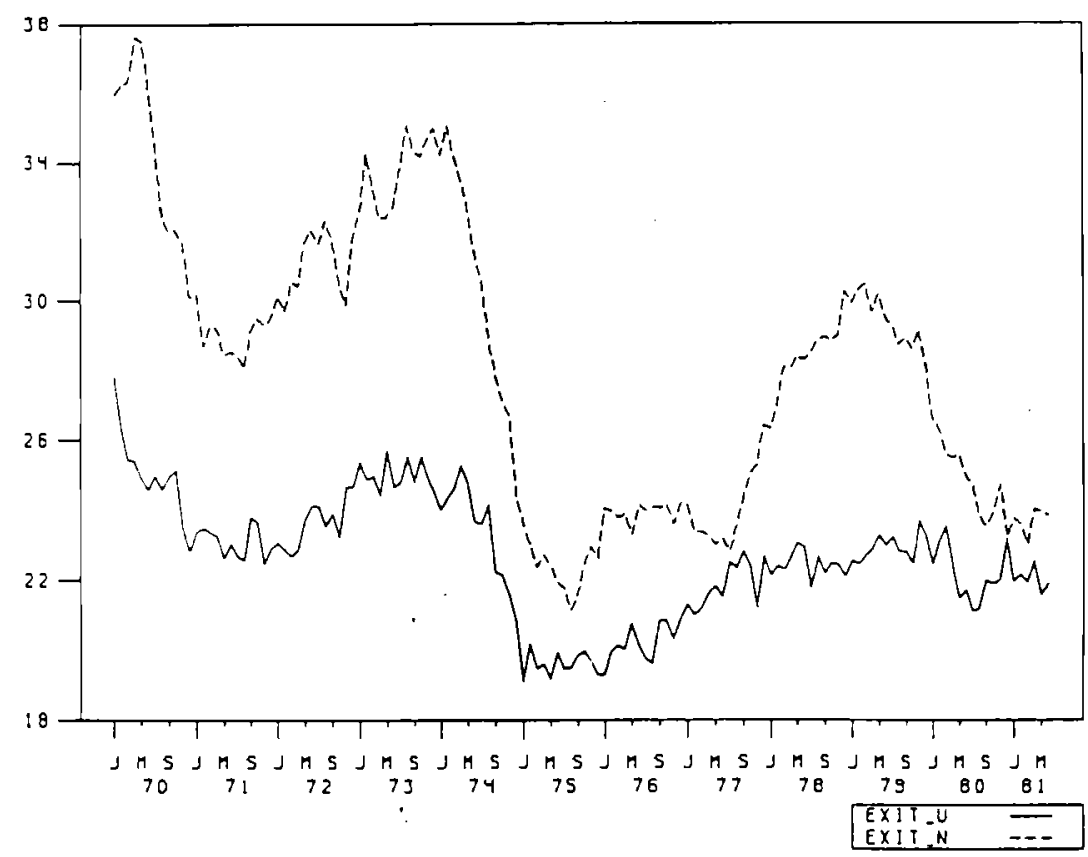


Table 4. The aggregate matching function Looking at the two pools separately

Independent variables : coefficients on :

constant $\underset{\left(\times 10^{-2}\right)}{\text { time }} \ln (\mathrm{V}(-1)) \ln (\mathrm{U}(-1)) \ln \left(\mathrm{N}(-1)\right.$ RTS DW $\mathrm{R}^{2}$

Dependent variable:

$\ln (H U)$
(1) (OLS)
.1 .01
.10
.01
.57
(0.0) (4.5)
$.57 \quad 2.2 \quad .71$
(2) (OLS)
$-1.20 \quad-.05$

$.18 \quad .81$
(6.0) (26.9)
$1.0 * \quad 2.1 \quad .71$
(SF-.05)
(3) (IV)
.1 .04
.07
03
.60
(0.2) (2.3)
$63 \quad 2.2 \quad .71$

$\ln (\mathrm{HN})$

(4) (OLS)

$-0.12$

.59

(6.7)

.21

$(0.7)$

(5) (OIS)

$-0.28-.21$

.62

(9.7)

$\begin{array}{llll}.37 & 1.0 * \quad 2.7 & .29\end{array}$

$.37 \quad(5.8) \quad(S F=.57)$
$(5)$

(6) (IV)

$\begin{array}{lll}-0.47 & -.27 & .63\end{array}$

(4.2)

.56

$(0.7)$

$\begin{array}{lll}1.19 & 2.6 \quad .28\end{array}$

$\ln (\mathrm{HU})$

(7) (OLS

$-1.03 \quad .10$

$\begin{array}{ll}.00 & .55 \\ (0.0) & (2.4)\end{array}$

.03

$(0.1)$

$\begin{array}{lll}.58 & 2.2 \quad .71\end{array}$

$\ln (\mathrm{HN})$

$\begin{array}{lllllllll}\text { (8) (OLS) } & -0.25 & -.11 & .48 & -.25 & .53 & .76 & 2.7 & .29\end{array}$

Period of estimation : $70: 2$ to $81: 12$

$t$ statistics in parentheses

Instruments for ( 3$),(6): \ln ($ IP), lagged one to three times;

IP : industrial production

RTS denotes the estimated degree of resurns to scale

A star indicates that constant returns was imposed in estimation.

$S F$ is the significance level of the test that returns are constant. 
The assumption made in table 3 that the various groups are the same up to a scalar is not very satisfactory. As hires from unemployment and from out of the labor force are available separately, we can relax the assumption further and look at the respective role of the two groups in the matching process.

Figure 2 shows the behavior of the pool of unemployed, $U$, and the pool of workers out of the labor force, N. $U$ is defined as above. N is taken to be those workers "out of the labor force but wanting a job". The series is available from 1970 on. (For ease of interpretation and comparison to the flows, $U$ and $N$ are divided by 10 in the figure). The figure also shows the flow of hires from unemployment, HU, and from out of the labor force, $\mathrm{HN}$. These flows are the CPS flows adjusted by Abowd and Zellner. $\mathrm{HU}$ is further modified to eliminace recalls, as explained earlier. The recall series is available until 1981, so that the figure and the regressions below are for the period 1970-1981. As we mentioned earlier, the flows have a large white noise component, due mostly to sampling error. The series plotted in figure 2 are centered 12 -month moving averages of the original series. Figure 3 shows the exit rates from each of the two pools, using the filtered hire series, $\mathrm{HU} / \mathrm{U}$ and $\mathrm{HN} / \mathrm{N}$.

A number of features clearly emerge from the two figures. The first is that the two pools, N and $U$ have similar cyclical behavior, the movements in $N$ being of smaller amplitude. The second is that the flows $H U$ and $H N$ have sharply different cyclical behavior. The flow of hires from unemployment is highly councercyclical, the flow of hires from out of the labor force procyclical. The third is that the exit rates are both procyclical. While HU increases when unemployment increases, the elasticity of HU to $\mathrm{U}$ is less than one, so that the exit rate still decreases with the level of unemployment. But the decline in the exit rate is much more dramatic for those out of the labor force than for those unemployed. Note that the exit rate from out of the 
labor force is on average higher than that from unemployment: this is implausible and suggests that the pool of those out of the labor force but wanting a job actualiy underestimates the size of the relevant pool of workers out of the labor force.

Table 4 in curn gives a number of simple regressions. Matching functions do not have a simple functional form when there are two types of workers, with possibly different search intensity by type, and possibly ranking of the two types by firms when there are multiple applications. Thus, the $\log$ linear specifications of table 4 which give hires from each pool as a function of the two pools and of vacancies (aIl in logarithms) should be taken only as data descriptions, or as log-linear approximations to yet underived matching functions. Two main features emerge from the table, the lack of significance of vacancies in explaining hires from unemployment, and the strong significance of vacancies in explaining hires from out of the labor force.

How may one interpret those facts? We can think of workers in the two pools as differing in three ways. They may differ in how their search intensity varies with market conditions. They may also differ in their rejection rate : firms may choose, other things equal, an unemployed worker over one who has been out of the labor force. Finally, the composition of the pools may change, making workers more or less acceptable to firms. The fact that the exit rate for those out of the labor force decreases more sharply than for those unemployed as markets conditions deteriorate may come from any of those sources. It may come from a decrease in the search intensicy of those out of the labor force relative to the unemployed. It may come from a deterioration of the quality of the pool of those out of the labor force relative to the unemployed. It may come from an increase in the rejection rate of those out of the 
labor force relative to the unemployed. If firms choose the unemployed over others, a larger number of unemployed workers will make it relatively harder for those out of the labor force to find and be accepted for jobs. We speculate that all those effects are at work. The fact that the flow from unemployment actually increases when the total flow into employment decreases cannot be generated by the pure ranking effect ${ }^{9}$. The (weak) statistical evidence presented in the last two regressions of table 4 that, given vacancies, the pool of unemployed has a negative effect on hires from out of the labor force, while the reverse is not true is suggestive of ranking effects. Confirming those speculations requires the derivation of an appropriate matching function, something we are currently working on.

We now embed the aggregate matching function in a model of the labor market, which we simulate.

8 The model we have in mind is a model in which firms post vacancies and receive a random number of applications, which can be equal to zero or one or more. what we call pure ranking is the case where firms, if they have the choice between unemployed workers and workers from out of the labor force, always choose the unemployed worker. We explore a model along those lines in Blanchard and Diamond (1989b). 
2. A Minimalist Model of Vacancies and Unemployment

To concentrate on the basic implications of large gross flows and an aggregate matching function, we leave out most of the texture of actual labor markets ${ }^{9}$. We think of the economy as being composed of identical workers and jobs. Workers can be in one of three states: let $E$ be the number of employed workers, $U$ the number of unemployed. and $\mathrm{N}$ the number of workers not in the labor force. Drawing a sharper distinction than exists, we assume that the unemployed look for work, those out of the labor force do not. We take the labor force, $\mathrm{L}$, as given. The first relevant equation is therefore:

$$
L-E+U
$$

Jobs can also be in one of three states: they can be either filled, unfilled with a vacancy posted ("vacancies" for short), or unfilled with no vacancy posted ("idle capacity"). Each job requires one worker. As with workers, we draw a sharper distinction between unfilled jobs with or without a vacancy posted than is true; only those jobs for which a vacancy is posted are looking for workers. Let $\mathrm{K}$ be the total number of jobs; $F$, the number of filled jobs; $V$, the number of vacancies; and $I$, the number of unfilled jobs with no vacancy posted -idle capacity-. Thus,

9 Ours is not the first model of vacancies and unemployment. We build on the early work of Hansen (1970) and Holt and David (1966). Our work also parallels work by Pissarides (1985) and (1987). We differ from his approach in treating the number of potentially productive jobs as given at any point of time; this has important implications for the joint dynamics of unemployment, vacancies and wages. 


$$
K=F+V+I
$$

Obviously $F$ and $E$ are identically equal. We take $K$ as given and constant. Note that by taking $K$ and $L$ to be constant, we treat the two sides of the market in asymmetric fashion: our focus here is on shocks to the supply of jobs, not on shocks which affect whether workers decide to enter or leave the labor force.

We think of each of the $K$ jobs in the economy as capable of producing a gross (of wages) revenue of either 1 or 0 . Productivity for each job follows a Markov process in continuous time. A productive job becomes unproductive with flow probability $\pi_{0}{ }^{10}$. An unproductive job becomes productive with flcw probability $\pi_{1}$. Thus, the times to a change in productivity are poisson processes. At any point in time, some jobs become productive, some jobs become unproductive. Whether newly productive jobs are jobs which were previously unproductive, or simply new jobs, is purely a matter of interpretation in the absence of recalls in the model. This is the mechanism we use to generate the large gross flows of job creation and job destruction that exist in the economy. By making this process mechanistic (not dependent on underlying decisions) we have a simpler (albeit less accurate) settirg for focusing on the complexity of aggregace dynamics.

\section{The equations of motion}

We combine these assumptions with the aggregate matching function described above. To complete the specification, we make the further assumption that job terminations are

10 That is, in any short interval of time $\Delta t$ there is a probability $\pi_{0} \Delta t$ of the job becoming unprofitable. 
not the only source of separations, but also that workers quit jobs at an exogenous, constant rate, $q$. We introduce quits partly for the sake of -some-realism, but also because there is a basic distinction between quits and job terminations in the model. A quit is associated with the posting of a new vacancy, a job termination is not. Here again, the distinction is sharper in the model than in actual labor markets, where quits are often used by firms to reduce their labor force, and are not always replaced. The assumptions that the quit rate is constant and that all quits are to unemployment, are both counterfactual, but not central to the issues at hand.

It follows from our assumptions that the behavior of the labor market is given by a system of two differential equations, which are:

$$
\begin{aligned}
& d E / d t=a m(U, V)-q E-\pi_{0} E \\
& d V / d t=-a m(U, V)+q E+\pi_{1} I-\pi_{0} V
\end{aligned}
$$

We consider these equations in turn, starting with the behavior of employment. When a job becomes unproductive, there is no reason for the worker to remain on the job.

Thus, the flow from employment to unemployment from this source is equal to $\pi_{0} E$. In addition, the flow of quits is equal to $q E$. The flow from unemployment to employment is equal to new hires.

For a job to produce 1 , it must not only be productive but also be matched with a worker. To do so, a vacancy must be posted and a worker must be recruited. There are thus two sources of new vacancies. The first, a flow from $I$ to $V$, comes from the fact that jobs which were previously unproductive have become productive; this first flow is equal to $\pi_{1} I$. The second, a flow from $F$ to $V$, comes from the need to replace workers who quit: it is equal to $q E$. Vacancies decrease for two reasons: some are filled by new hires, a flow from $V$ to $F$; some of the jobs for which vacancies were posted become unproductive, a flow from $V$ to $I$. We assume that vacancies become unproductive at the same rate as filled jobs. 
Using the identities above, these equations can be rewritten as a system in unemployment and vacancies, given $K$ and $L$ :

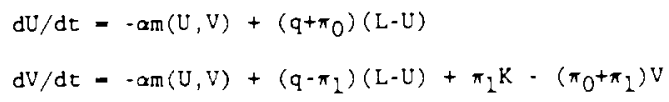

This account of the labor reallocation process has not mentioned wages. Wages are likely to affect $K$ and $L$ as well as $\pi_{0}$ and $\pi_{l}$. But we take $K, L_{1} \pi_{0}$ and $\pi_{1}$ as given in this model. Wages could also affect whether or not a meeting between a worker and a firm actually leads to a hiring, thus affecting m or $\alpha$. We assume that wages do not affect matching. That is, we consider a sizuation where first the worker and the firm examine whether there is a mutually advantageous opportunity to begin an employment relationship. If there is, they then negotiate a wage to divide the surplus from the match with no constraint (e.g. fairness, union contracts, or posted wages) on allowable bargains. In a richer model with heterogeneous workers, jobs and matches, the nature of bargaining power between the two sides would affect allocation by affecting expectations about future opportunities. We ignore such complications, explicitly assuming homogeneous workers and firms, absorbing the implications of heterogeneity into the parameters of the model. In this way, we can focus on unemployment and vacancies, ignoring wage and price dynamics. Then we can examine wage dynamics wich labor market quantities given.

\section{Steady state and dynamics}

Setting $d U / d t$ and $d V / d t$ to zero, we have the steady state values of $V$ and $U$ satisfying:

$$
\begin{aligned}
& \alpha m(U, V)=\left(q+\pi_{0}\right)(L-U) \\
& \alpha m(U, V)=\left(q-\pi_{I}\right)(L-U)+\pi_{1} K-\left(\pi_{0}+\pi_{1}\right) V
\end{aligned}
$$




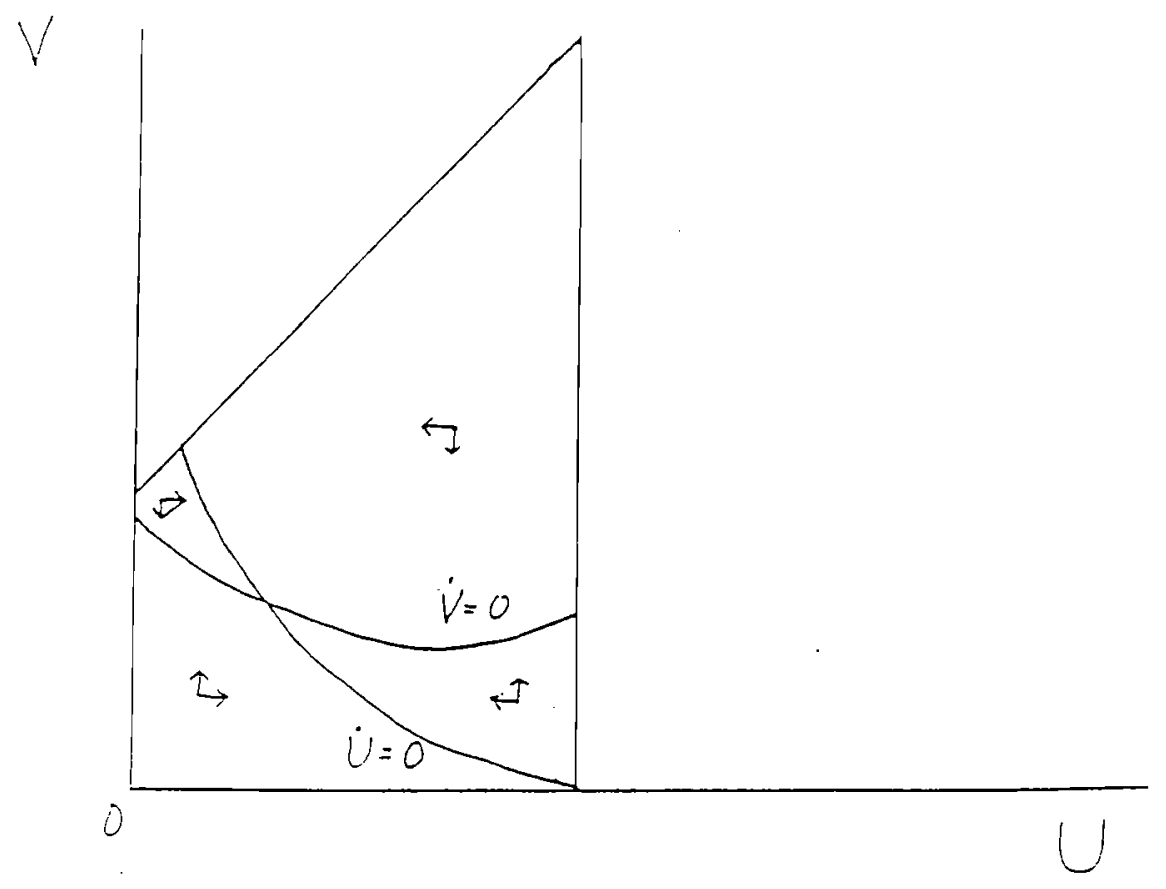

Figure 4. 
Figure 4 shows these stationary curves and directions of motion. The relevant region of the plane has $U, V, E$ and $I$ all non negative. The locus dU/dt - 0 is downward sloping. It does not hit the $V$ axis given that $m$ is equal to zero if $V$ is equal to zero. The locus $d V / d t=0$ need not be monotonic. Nevertheless there is a unique equilibrium, which is a stable node.

To think of the dynamics of $U$ and $V$, we have to specify the sources of shocks to the economy. It is natural to think of changes in $\pi_{0}$ and $\pi_{1}$ as the important source of fluctuations in the system. But looking at changes in. one $\pi$ keeping the other constant does not appear to be a particularly relevant experiment. We find it more attractive to think in terms of shocks to aggregate activity and to the degree of reallocation. For this purpose, we define two other parameters, $c$ and $s$, in terms of $\pi_{0}$ and $\pi_{1}$. For given $\pi_{0}$ and $\pi_{1}$, the proportion of potential jobs which are productive in steady state is given by $\pi_{1} /\left(\pi_{0}+\pi_{1}\right)$; we may think of this proportion, which we shall callc (for cycle) as measuring the degree of aggregate activity (or more precisely potential aggregate activity, as the proportion of jobs productive and filled will always be less than c). In steady state, the instantaneous flow of jobs changing from productive to unproductive (which equals the reverse flow), is equal to $\pi_{0} \pi_{1} /\left(\pi_{0}+\pi_{1}\right.$ ) times $\mathrm{K}$; we can think of this ratio, which we shall denote $s$ (for shift), as an index of the intensity of reallocation in the economy.

Since $\pi_{0}-s / c$ and $\pi_{1}=s /(1-c)$, we can rewrite the dynamic system in terms of $s$ and $c$ :

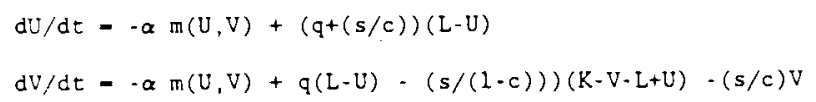

These equations provide a dynamic characterization of the Beveridge relation- the joint behavior of unemployment and vacancies in response to either aggregate activity 
T. . .

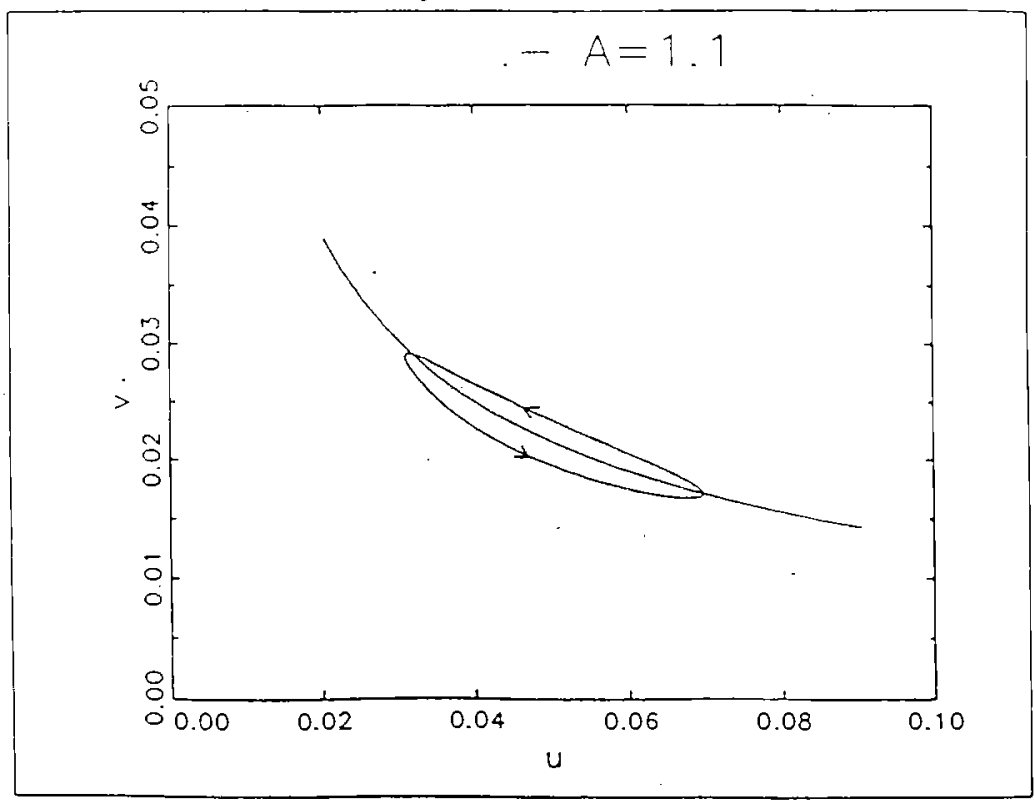

Figne 6

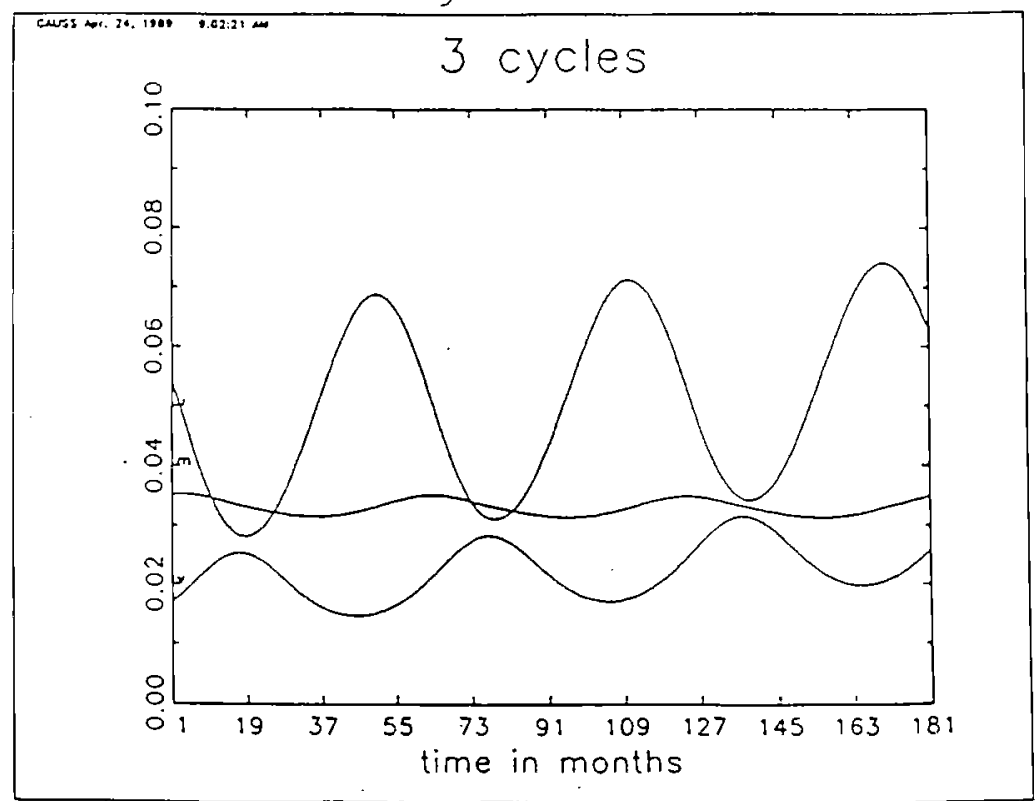


or reallocation shocks. In our BPEA paper, we analyze those dynamics. We just sumarize them here. Changes in aggregate activity, c, lead to opposite movements in unemployment and vacancies, with dynamics that are generally counterclockwise around the steady state locus. Figure 5 plots the downward sloping locus giving the steady state values of $U$ and $V$ corresponding to alternative values of $c$. It also plots the dynamics of adjustment of $U$ and $V$ to a sine wave in $c$. Either the steady state locus or the loops are what most people have in mind when referring to "the" Beveridge curve In contrast, changes in the intensity of reallocation, $s$, or in the effectiveness of matching, a, move unemployment and vacancies in the same direction, actually along a 45 degree line if the economy starts from a steady state position. This contrast in directions of motion in response to different shocks is key for the empirical work reported below.

The model clearly captures the idea that high unemployment can be due either to aggregate activity factors, or to structural changes requiring the reallocation of labor, and the idea that looking at both unemployment and vacancies can shed light on the sources of unemployment movements. While there are a number of ways in which this minimalist model can be enriched - and we discuss a number of them in our BPEA paper-it is fun at this point to return to the estimated matching function and use it to simulate the economy.

For the simulation shown in figure 5, we take the matching function to be cobb Douglas, with constant returns and coefficient, 4 on unemployment. We choose the scale parameter, A, to be 1.1 (the estimated scaie parameter has a trend and goes from 1.30 at the beginning to .95 at the end of the sample). For the rate of quits (remembering that only quits that are replaced are relevant) we choose. 01 , which is the minimum manufacturing quit rate in the period. The other parameters are then chosen so as to 
approximate sample averages for unemploymen, vacancies and mean hires. This leads to choices of 1.05 for $(\mathrm{K} / \mathrm{L})$, the ratio of potential jobs to workers, .023 for 5 , the reallocation parameter, and .925 for the central value of $c$, the potential activity level. These values imply an arrival rate of good profitability shocks, $\pi_{1}, 0 f .307$ and an arrival rate of bad profitability shocks, $\pi_{0}$, of .025 . The values of $q$ and $\pi_{0}$ imply in turn an average duration of a match of 2.5 years. For the steady state locus, we let c vary between .88 and .97 . To trace out a cycle, we let c be a sine wave between . 90 and .95, with a period of five years. In this simulation, shown in figure 5, at a vacancy rate of 2 for example, unemployment is roughly lo higher when the economy is expanding than when it is contrasting. With a decrease in the efficiency of inatching, both the steady state locus and the counterclockwise loops would move diagonally to the northeast. A horizontal shift to the right in both curve and loop would come from the combination of a decrease in the efficiency of matching and a lower level for the cycle of aggregate activity.

In figure 6, we show time paths of new hires, $m$, unemployment and vacancies from a simulation of the model with a .0018 downward trend in the efficiency of matching. This figure can be compared with figure 1 which gives the observed time series. To reproduce the greater rise in unemployment in figure 1 would require a drop in the average level of aggregate activity, $c$, in addition to the decline in the matching function. 
3. Wage Determination

In the theory underlying the analysis ajove, wage setting does not prevent a match from happening if it is mutually profitable. A natural and appealing formalizacion with this property is that the surplus from matching a worker and a firm is shared in some proportion, an assumption of Nash bargaining. We adopt this assumption and explore its implications.

For notational convenience, we set the flow of benefits of unemployed workers and vacancies equal to zero. The total flow of benefits from employment is the excess of net output over the sum of these two flows ${ }^{11}$; we denote it by $y$. We consider risk neutral workers and firms who all face the same interest rate and have the same expectations about the future. The gain to a worker from becoming employed is the difference between the expected present discounted value of wages when one is currently employed and the expected present discounted value of wages when one is currencly unemployed. We denote this difference by $D$ :

$$
D-w_{e}-w_{u}
$$

where $w_{j}$ is the expected present discounted value of income in different current states. The joint gain from beginning the employment relationship is $w_{e} \cdot w_{u}+w_{f} \cdot$

11 Thus, this analysis can be converted into the more general analysis by adjusting the wage for the benefit flow when unemployed and adjusting net output for both the profit flow (presumably negative) from a vacancy and the benefit flow from being unemployed. 
$W_{V}$, where $W_{f}$ and $W_{V}$ are the present discounted values of profit from the ownership of a job when the job is currently filled and vacant respectively. The problem of bargaining is to divide this surplus betweer the two parties. We assume that the proportional division of surplus does not vary. Thus, we can write

$$
D=W_{e}-W_{u}-z\left(W_{f}-W_{v}\right)
$$

With both parties risk neutral and using the same discount rate, there are many wage patterns which will satisfy (13), provided they have the same expected present discounted value. We first consider the situation where wages are continuously renegotiated to continuously satisfy (13). Thus all employed workers are earning the same wage.

To derive the present discounted value equations, we use the standard dynamic programing or arbitrage equation approach. The discount rate times the present discounted value is equal to the flow of benefits plus the capital gains from changes in position and from changes in the parameters of the economy. Thus

$$
\begin{aligned}
& r w_{e}=w+\left(\pi_{0}+q\right)\left(w_{u}-w_{e}\right)+d w_{e} / d t \\
& r w_{u}=\quad(a m / U)\left(w_{e}-w_{u}\right)+d w_{u} / d t
\end{aligned}
$$

That is, when employed one receives the wage $w$, the employment relationship ends with flow probability $\left(\pi_{0}+q\right)$. the sum of the rates of bad productivity shocks and exogenous quits, and the value of being emp-oyed changes as the unemployment and vacancy rates change ${ }^{12}$. When unemployed, one is receiving no benefit flow (by normalization) and one has the flow probabizity am/U of finding a job. Similarly, we have

12 Remember that our model does not allow for quits from a job directly to another job. 
(15)

$$
\begin{aligned}
& r W_{f}=y-w+\pi_{0}\left(W_{i}-W_{f}\right)+q\left(W_{v}-W_{f}\right)+d W_{f} / d t \\
& r W_{v}=\quad(a m / v)\left(W_{f}-W_{v}\right)+\pi_{0}\left(W_{i}-W_{v}\right)+d W_{v} / d t \\
& r W_{i}=y^{\prime}+\pi_{1}\left(W_{v}-W_{i}\right)
\end{aligned}
$$

where $y^{\prime}$ is the saving in costs from idling capacity rather than searching for a worker and keeping capacity ready to produce.

Subtracting the equations in (14) and (15) and using the definition of $D$ in (13) as well as the time derivative of (13) we have

$$
\begin{aligned}
& (r+\pi 0+q+(a m / v)) D-w+d D / d t \\
& (r+\pi 0+q+(a m / v)) D-z(y-w)+d D / d t
\end{aligned}
$$

From (16), we obtain an equation relating the wage to the gain from becoming employed and a differential equation for that gain. These can be rewritten as:

$$
\begin{aligned}
& (1+z) w-z y+[(\alpha m / U)-(\alpha m / v)] D \\
& (1+z) d D / d t-\left[(1+z)\left(r+\pi_{0}+q\right)+(\alpha m / N)+z(\alpha m / J)\right] D-z y
\end{aligned}
$$

In steady state, $i . e$. when $D$ is constant, the wage reduces to the simpler expression:

$$
\left.w / y-\left(r+\pi_{0}+q+\alpha m / U\right) z /\left(\left(r+\pi_{0}+q\right)(1+z)+z(\alpha m / U)+\alpha m / V\right)\right)
$$

Finally, if we assume $a m / U$ and $a m / N$ to be iarge compared to $r, \pi_{0}$ and $q$, w is approximately equal to:

$$
\mathrm{w}=\mathrm{y}(\mathrm{zV} /(\mathrm{zV}+\mathrm{U}))
$$

While equation (18') only holds as an approximation and in steady state, it is likely to be a good approximation to the wage even out of steady state. This is because $(\alpha m / V)$ and thus the discount rate in the second equation in (17) is large, so that the future does not matter very much, and because $r, \pi_{0}$ and $q$ are small compared to the values of $\alpha m / U$ and $\alpha m / v^{13}$.

13 with monthly data, $\alpha \mathrm{m} / \mathrm{U}$ is equal to approximately $308, \mathrm{am} / \mathrm{V}$ equal to approximately 1008. In contrast $r, q$, and $\pi_{0}$ are all less than 58 . 
Equation $\left(18^{\prime}\right)$ shows how the wage moves with the vacancy/unemployment ratio, which reflects the arrival rates of alternative opportunities, and with the bargaining parameter $z$. Thus changes in aggregate activity, by moving unemployment and vacancies in opposite directions, will have a strong impact on the wage. But changes in reallocation, by moving unemployment and vacancies in the same direction, will have a much smaller effect on the wage.

Equation (17) together with the equations of motion for $U$ and $V$ derived in the previous section give a characterization of the joint dynamics of $U, V$ and wiven $c, s$ and $z$. A natural step is to return to the simulation of the last section, which examines the effects of cyclical movements in $c$. This is done in figure 7 , using values of 1 for $y, 1$ for $z$ and .48 per month for the real interest rate.

A striking feature of the figure is the large procyclical movement in w over the $c$ cycle, an unpleasant implication in view of the actual behavior of the wage. However, as we mentioned earlier, there is no reason why the wage should always be equal to the instantaneous wage derived in (17). New matches may well agree to pay a constant real wage over some (possibly stochastic) time period, with the wage chosen in new matches equal to the annuity value of the wage in (17) 14 . For example, there might be a constant real wage for the life of the match. This will substantially decrease the amplitude both of the wage on new contracts, plotted as $w_{1}$ in figure 7 , and of the current average wage, the average of the wages in force in existing matches, win

14 Although in this case, we have to add the assumption that workers do not quit to improve their lot, a possibility which arises when wages are not equal and workers are not bound to their contracts. 


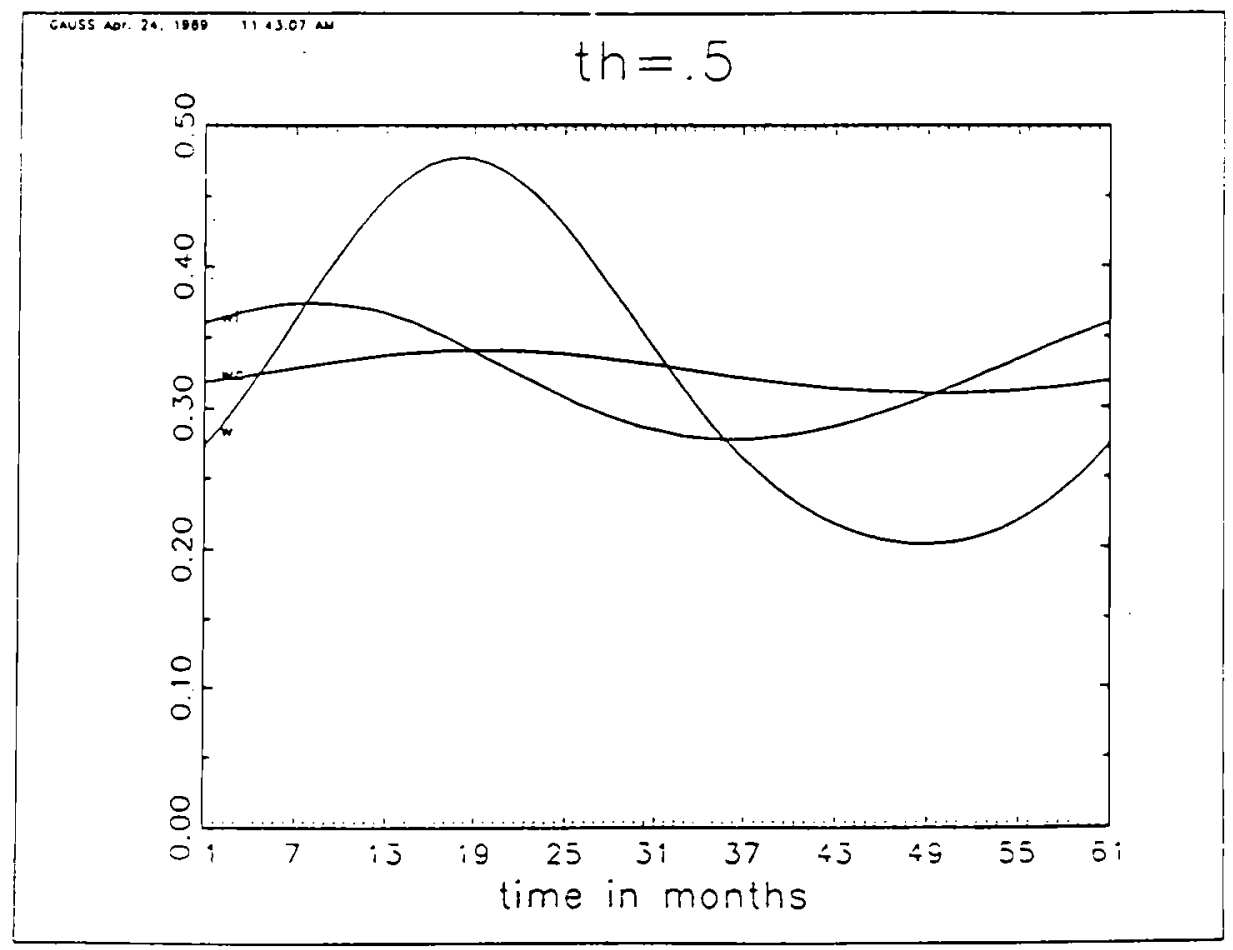

Figure 7 
figure 7. The addition of a constant positive value of time when unemployed would reduce the size of the proportional fluctuations in the wage, since wages would equal this constant plus the calculated fraction of the excess of output over this constant. Similarly and moving towards the introduction of nominal rigidities, it is easy to consider contracts that are fixed in nominal terms for, say, a year and then calculate the average nominal wage in force at any point.

Even with those extensions, this theory of wage determination does not capture important aspects of the labor market. A more ambitious rask would be to consider wage setting mechanisms which may sometimes prevent mutually beneficial matching from taking place. We have in mind here preset wages or union-negotiated wages. Indeed one of the challenges of this approach is to combine partially centralized wage setting - which we observe along with wage drift-and a description of the market which allows for the large flows of workers. These extensions are on our agenda. 
4. Looking at unemployment, vacancies and wages.

The last two sections have developed a view of fluctuations in unemployment, vacancies and wages as coming from movements in aggregate activity, in the intensity or effectiveness of reallocation, in the bargaining power of workers and firms, and in productivity $y$. The model is simple, leaving many important aspects of the labor market out; even so, it suggests an appealing empirical strategy if our goal is to understand the origins of movements in unemployment.

Define the Beveridge curve and the Phillips curve as the loci traced by unemployment and vacancies, and by unemployment and wages - leaving again aside the delicate issues of nominal versus real wages - in response to changes in c. Thus, by definition, movements in $c$ lead to movements along the Beveridge curve and along the Phillips curve. In contrast, changes in reallocation intensity or effectiveness lead to shifts in both the Beveridge curve and the Phillips curve. Changes in bargaining power lead to shifts in the Phillips curve, but not in the Beveridge curve. One can think of more complex patterns: a long period of low aggregate activity which leads to a decrease in the effectiveness of matching will lead to movements along the curves as well as shifts in the two curves. Thus, by looking at movements on and shifts in the curves, we can learn something about the sources of fluctuations. This was the avenue explored by Solow in his wicksell lectures (1964). A similar approach has been used more recently by Layard and Nickell in their analysis of unemployment in the UK (1986).

We have not yet put together a full story along these lines for the US. One obvious problem is the need to go from the wage equation in (17) to an equation which recognizes, among other things, the presence of nominal rigidities and the stochastic 


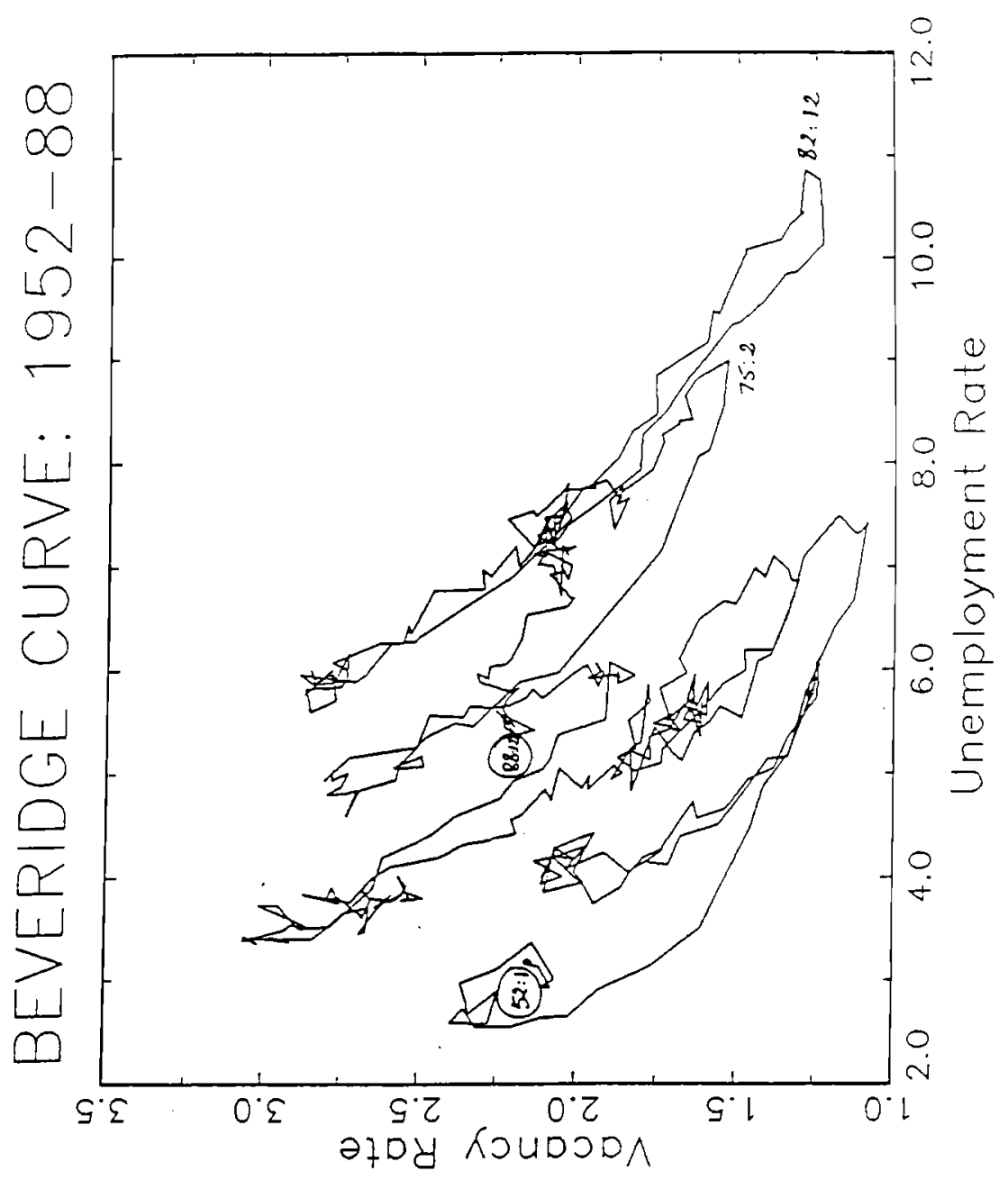


nature of productivity. But we have started. First, we have looked at the Beveridge relation to learn about the relative importance and the dynamic effects of the different shocks. With its recursive structure, our model suggests that we can indeed look at the Beveridge relation by itself. And we have peeked at the wage equation.

\section{The Beveridge curve}

The relation between monthly unemployment and vacancy rates in the Us over the period $48: 1$ to $88: 12$, using the same measure of vacancies as in Section 1, is plotted in figure 8. The relation has two clear features. The first is the large thin loops around a downward sloping locus. The other is the shift to the right over the post war period. This shift has been well documented (Abraham and Medoff (1982) for example). Interestingly, it has substantially reversed over the last four years: from $84: 12$ to $88: 12$, the vacancy rate has remained roughly constant while the unemployment rate has decreased by 28 .

Our approach suggests a simple interpretation, one which has been given by Abraham and Katz (1986): the large loops suggest that aggregate activity shocks dominate short and medium run movements in unemployment. The shifts to the right and then to the left suggest a role for changes in reallocation intensity or effectiveness, but at lower Erequencies. What we now present uses more formal econometric techniques but reaches the same basic conclusions. Our presentation is informal and the reader is referred to our BPEA paper ror details.

We consider the joint behavior of $U, V$ and $L$. While we assumed in our formalization that the labor force was constant, we now need to relax this assumption: we saw earlier that 408 of new hires came from people classified as out of the labor force; the 
endogeneity of the labor force with respect to employment is a well documented part of Okun's law. We assume that movements in $\mathrm{V}, \mathrm{V}$ and $\mathrm{I}$ come from their dynamic responses to three types of shocks, aggregate activity shocks, c, changes in reallocation intensity or effectiveness, $s$ (or $\alpha$, as they have the same dynamic effects), and exogenous changes in the labor force, $f$. Those shocks are in turn assumed to follow stochastic processes with white noise innovations $\epsilon_{c}, \epsilon_{S}$ and $\epsilon_{f}$ respectively. When we look at the joint behavior of $U, V$ and $L$, as characterized by a VAR, we can therefore think of the innovations in $\mathrm{U}, \mathrm{V}$ and $\mathrm{L}$ as being linear combinations of the three $\epsilon$ 's. To achieve identification of the $\epsilon^{\prime} s$, we make a number of identifying restrictions. The two essential ones are the following.

First, we assume the $\epsilon^{\prime} s$ to be mutually uncorrelated. While this is unlikely to be true, we think of them as coming from largely different sources so that the assumption is an acceptable first approximation. Second, we assume that $c$ innovations affect unemployment and vacancies in opposite directions for at least nine months, and that $s$ innovations affect unemployment and vacancies in the same directions for at least nine months. This in effect defines the two types of innovations. These restrictions are sufficient to pin down fairly precisely the $\epsilon^{\prime} s$. Once this is done, it is easy to decompose the movements in the unemployment and vacancy rates into those parts which are due to each of the three shocks. Figures 9 a to $9 \mathrm{~d}$ decompose the historical movements in the unemployment and vacancy rates into the components due to each shock and to the deterministic component - the movement in unemployment and vacancy races which would have occurred, had all realizations of shocks been identically equal to zero during the period. Those figures confirm and extend our earlier visual impression.

In the short and medium run, aggregate activity shocks have, by far, the largest effects on the unemployment and vacancy rates, and generate the predicted 
Figure 9
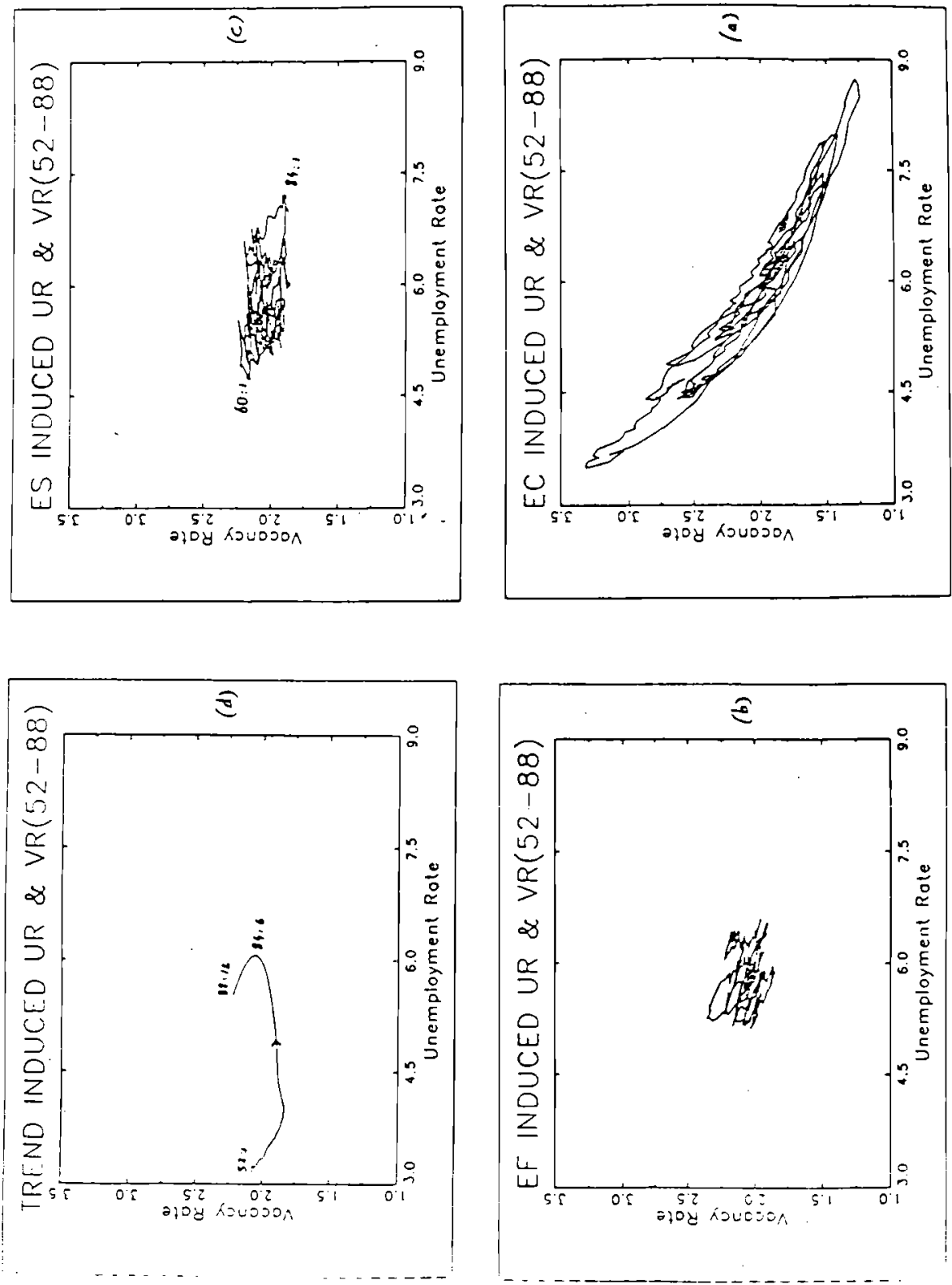

5
if 
counterclockwise loops. Reallocation and :abor force shocks have small effects, and the movements implied by reallocation shocks are initially much flatter than the movements along a 45 degree line predicted by the theory. There are large flows of job creation and destruction in the US, but changes in the intensity of the reallocation process do not appear to be an important determinant of short run unemployment fluctuations.

However, part of the longer run shift in the Beveridge relation in the post war period is attributable to the long run effects of reallocation shocks. The movements due to changes in aggregate activity, given in figure $9 \mathrm{a}$, are large but, interestingly, account for none of the drift in the relation over the period. The movements due to labor force shocks in figure $9 b$ account for small movements of UR and VR and again for none of the drift. The movements due to changes in reallocation activity or effectiveness, given in figure $9 c$, however account for a steady movement of the unemployment rate upwards, by 2 from the late 60 's to 1984 , followed by a decrease of roughly 18 since. Long run effects of reallocation shocks however are not the whole story. The deterministic component, given in figure 9d, traces an increase in unemployment of 38 from the early 50's to 1984, followed again by a decrease of 18 since, without much change in the vacancy rate over the whole period. Where does the deterministic component in turn come from? It may come from trends in the underlying shocks, such as, for example, movements in reallocation intensity steady enough to be captured by a deterministic rather than by the stochastic component, or from trend changes in matching, such as for example an increased geographical dispersion of workers and new jobs. The evidence presented earlier suggests that trend changes in matching, which we find in our estimation of the matching function for the period 1968 to 2981 , account for a good part of this deterministic trend. Of course, this just 
moves the mystery, telling us where to look for the culprit, but not yet explaining those shifes.

\section{The Phillips curve}

Our model implies that wages depend on both unemployment and vacancies. Thus, wages should respond strongly to movements in unemployment due to aggregate activity shocks, but weakly or not at all to movements in unemployment due to changes in reallocation. We have not yet developed wage equations we feel confident enough with to take to the data. What we have done therefore, as a first step, is to look at standard, time tested, Fhillips curve specifications to see what happens when we include both the unemployment and vacancy rates or, alternatively, when we include the components of unemployment due to different shocks that we derived above.

The two specifications we start from are:

(19) $\Delta W / W-a_{0}+a_{1} \Delta P_{c} / P_{c}+a_{2} E\left[\Delta P_{c} / P_{c}\right]+a_{3} U r+z_{w} a_{4}+\eta_{w}$

(20) $\Delta \mathrm{P} / \mathrm{P}=\mathrm{b}_{0}+\mathrm{b}_{1}(\mathrm{~L}) \Delta \mathrm{P} / \mathrm{P}+\mathrm{b}_{2}(\mathrm{~L}) \Delta \mathrm{P}_{\mathrm{m}} / \mathrm{P}_{\mathrm{m}}+\mathrm{b}_{3} \mathrm{Ur}+\mathrm{z}_{\mathrm{p}} \mathrm{b}_{4}+\eta_{\mathrm{p}}$

All variables are quarterly averages. The first equation is a conventional wage equation, close to the DRI wage equation for example. W and $P_{c}$ are the wage for the private non-farm economy and the urban CPI respectively. ur is the unemployment rate. $Z_{w}$ is a vector of dummies, including seasonals, wage price control dummies and a post 1973 dummy to proxy for the decline in productivity growth. Wage inflation is allowed to depend on current price inflation, on expected price inflation defined as a geometrically distributed lag of inflation, with decay parameter . 85 .

The second is a reduced form "price price" equation, implicitly combining the price and wage equations. It is similar to equations estimated by Gordon (1982) for example. 
The price variable, $P$, is the GNP deflator. $P_{m}$ is the crude materials PPI. $Z_{p}$ is a vector of wage price control dummies. Inflation is allowed to depend on four lags of itself, current and lagged rates of change of $P_{m}$, the unemployment rate and the vector of dummies.

Table 5 gives the results of estimation when both the unemployment and the vacancy rates are allowed to enter the wage and price equations. The conclusions are similar for both sets of equations. Both rates, when entered alone, have roughly the same explanatory power. The fact that vacancy rates do as well as or marginally better than unemployment has long been documented (Brownlie and Hampton (1967). Schultze (1971). Baily and Tobin (1977), Abraham and Medoff (1982)). The ratio of the unemployment rate to the vacancy rate, a specification suggested by equation (18'), does roughly as well or marginally better than either rate entered individually. When entered together, both rates however become insignificant. Given our findings earlier that movements in aggregate activity dominate short and medium run movements in unemployment, our inability to find a separate role for vacancies and unemployment may not be all that surprising. European countries with their sharper shifts in the Beveridge and Phillips curves may provide better playgrounds (the results of Jackman, Layard and Pissarides (1984), as well as preliminary evidence presented in Blanchard (1989) suggest that this is indeed the case).

Table 6 pursues the alternative of allowing the four components of unemployment to enter the equation separately. From the work on the Beveridge relation, we can decompose the unemployment rate into four components, Ur due to movements in aggregate activity, Urs due to movements in reallocation, Urf due to exogenous movements in the labor force and $U I_{t}$, the deterministic component. The potential advantage of this approach is that those components are uncorrelated by construction, in contrast to the highly collinear unemployment and vacancy rates. 
Table 5. Wages and Prices as functions of the Unemployment and the Vacancy rates.

1. Wage equation. Dependent variable : $\Delta \mathrm{W} / \mathrm{w}$ *

\begin{tabular}{|c|c|c|c|c|c|c|}
\hline$\Delta P_{c} / P_{c}$ & $E\left[\Delta \mathrm{P}_{c} / \mathrm{P}_{\mathrm{c}}\right]$ & U rate & $V$ rate & $\mathrm{U} / \mathrm{V}(\mathrm{x} 100)$ & $\rho$ & $R^{2}$ \\
\hline .00 & 84 & $\begin{array}{l}-.12 \\
(-2.9)\end{array}$ & & 5 & 6 & .84 \\
\hline .03 & .75 & & $\begin{array}{r}.31 \\
(2.4)\end{array}$ & & 60 & .83 \\
\hline .00 & .78 & $\begin{array}{c}-.12 \\
(-1.4)\end{array}$ & $\begin{array}{c}-.01 \\
(0.0)\end{array}$ & & 56 & .83 \\
\hline .02 & .78 & & & $\begin{array}{l}-.09 \\
(-2.5)\end{array}$ & 8 & .84 \\
\hline
\end{tabular}

Period of estimation: $64: 2$ to $87: 4$

$E\left[\Delta P_{c} / P_{c}\right]$ is defined by $E\left[\Delta P_{c} / P_{c}\right]=.85 \star E\left[\Delta P_{c} / P_{c}(-1)\right]+.15 \Delta P_{c} / P_{c}$

* : additional variables included, but not reported : constant, seasonal dumies, wage price concrol dumies, post 73 dumny.

2 Price equation. Dependent variable : $\Delta P / P$ *

\begin{tabular}{|c|c|c|c|c|c|}
\hline$\Delta P / P(1$ to 4 & $\Delta \mathrm{P}_{\mathrm{m}} / \mathrm{P}_{\mathrm{m}}(0$ to 4$)$ & U rate & $V$ rate & $U / V(x 100)$ & $\mathrm{R}^{2}$ \\
\hline .80 & .06 & $\begin{array}{c}-.03 \\
(-1.1)\end{array}$ & & & .66 \\
\hline .78 & .09 & & $\begin{array}{l}.14 \\
(1.3)\end{array}$ & & .66 \\
\hline 78 & .07 & $\begin{array}{c}-.01 \\
(-0.2)\end{array}$ & $\begin{array}{c}.10 \\
(0.6)\end{array}$ & & .66 \\
\hline 81 & .07 & & & $\begin{array}{c}-.05 \\
(-1.6)\end{array}$ & .66 \\
\hline
\end{tabular}

Period of estimation : $64: 2$ to $88: 4$

The first two numbers give the sum of the coefficients on the GNP deflator lagged one to four times, and on the crude materials PPI deflator, current and lagged one to four times.

* : additional variables included, but not reported : constant, wage price control dummies. 
Table 6. Wages and Prices as functions

of the componerts of unemployment

1. Wage equation.

Dependent variable: $\Delta W / W *$

\begin{tabular}{|c|c|c|c|c|c|c|c|c|c|}
\hline$\Delta P_{c} / P_{c}$ & $E\left[\Delta P_{c} / P_{c}\right]$ & $\begin{array}{c}\text { Ur } \\
\ldots .\end{array}$ & $\begin{array}{l}U_{c} \\
\cdots\end{array}$ & $U r_{f}$ & $\mathrm{Ur}_{\mathrm{S}}$ & $U r_{t}$ & $\mathrm{Ur}_{\mathrm{st}}$ & $\rho$ & $R^{2}$ \\
\hline .00 & .84 & $\begin{array}{c}-.12 \\
(-2.9)\end{array}$ & & & & & & .56 & .84 \\
\hline .02 & .72 & & $\begin{array}{c}-.13 \\
(-2.1)\end{array}$ & & & & & .59 & .83 \\
\hline .03 & .61 & & $\begin{array}{c}-.10 \\
(-2.5)\end{array}$ & $\begin{array}{c}.03 \\
(0.2)\end{array}$ & $\begin{array}{c}-.38 \\
(-4.0)\end{array}$ & $\begin{array}{r}1.13 \\
(4.9)\end{array}$ & & .14 & .87 \\
\hline .01 & .88 & & $\begin{array}{r}-.12 \\
(-2.0)\end{array}$ & $\begin{array}{r}-.24 \\
(-1.1)\end{array}$ & & & $\begin{array}{c}-.21 \\
(-1.4)\end{array}$ & .58 & .8 \\
\hline
\end{tabular}

Dependent variable : $\left(\Delta W / W-E\left[\Delta P_{c} / P_{c}\right]-\theta\right) \star \star$

\begin{tabular}{|c|c|c|c|c|c|c|c|}
\hline Ur & $U r_{c}$ & $U r_{f}$ & $\mathrm{Ur}_{\mathrm{s}}$ & $\mathrm{Ur}_{t}$ & $U r_{s t}$ & $\rho$ & $\mathrm{R}^{2}$ \\
\hline $\begin{array}{l}-.15 \\
-5.4)\end{array}$ & & & & & & .59 & .72 \\
\hline & $\begin{array}{c}-.16 \\
(-2.5)\end{array}$ & & & & & .73 & .69 \\
\hline & $\begin{array}{c}-.09 \\
(-2.4)\end{array}$ & $\begin{array}{l}-.29 \\
-1.9\end{array}$ & $\begin{array}{c}-.39 \\
(-3.7)\end{array}$ & $\begin{array}{c}.72 \\
(2.7)\end{array}$ & & .39 & .75 \\
\hline & $\begin{array}{c}-.12 \\
(-2.2)\end{array}$ & $\begin{array}{l}-29 \\
-1.6)\end{array}$ & & & $\begin{array}{c}-.24 \\
(-2.0)\end{array}$ & .60 & .72 \\
\hline
\end{tabular}

Period of estimation: $64: 2$ to $87: 4$

Price and wage variables defined as in table 3

$\mathrm{Ur}$ : unemployment rate; Ur $r_{c}, \mathrm{Ur}_{s}, \mathrm{Ur}_{f}$ and $\mathrm{Ur}_{t}$ : aggregate activity, reallocation, labor force and deterministic components of unemployment, obtained from Beveridge curve decomposition

* Additional variables included but not reported: constant, seasonal dumies. wage price control dummies, post 73 dumies

* The left hand side variable is equal to wage inflation minus expected inflation, minus fitted productivity growth, obtained as the projection of labor productivity on a quartic trend

2. Price equation Dependent variable: $\Delta P / P \star \star \star$

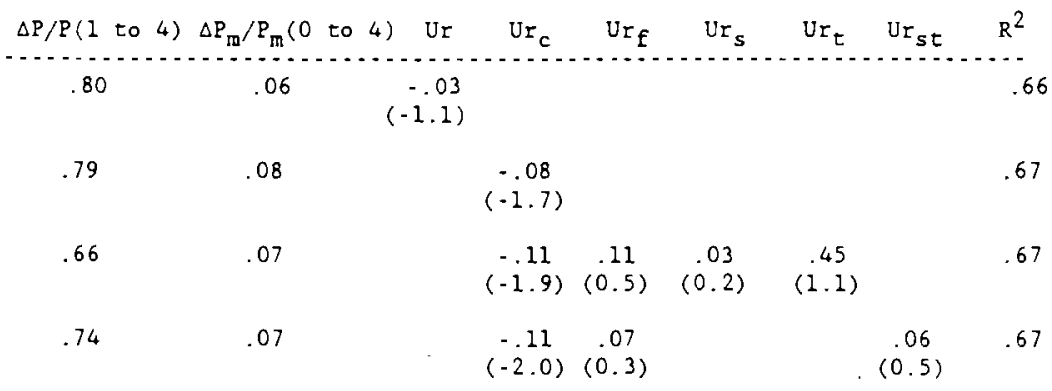




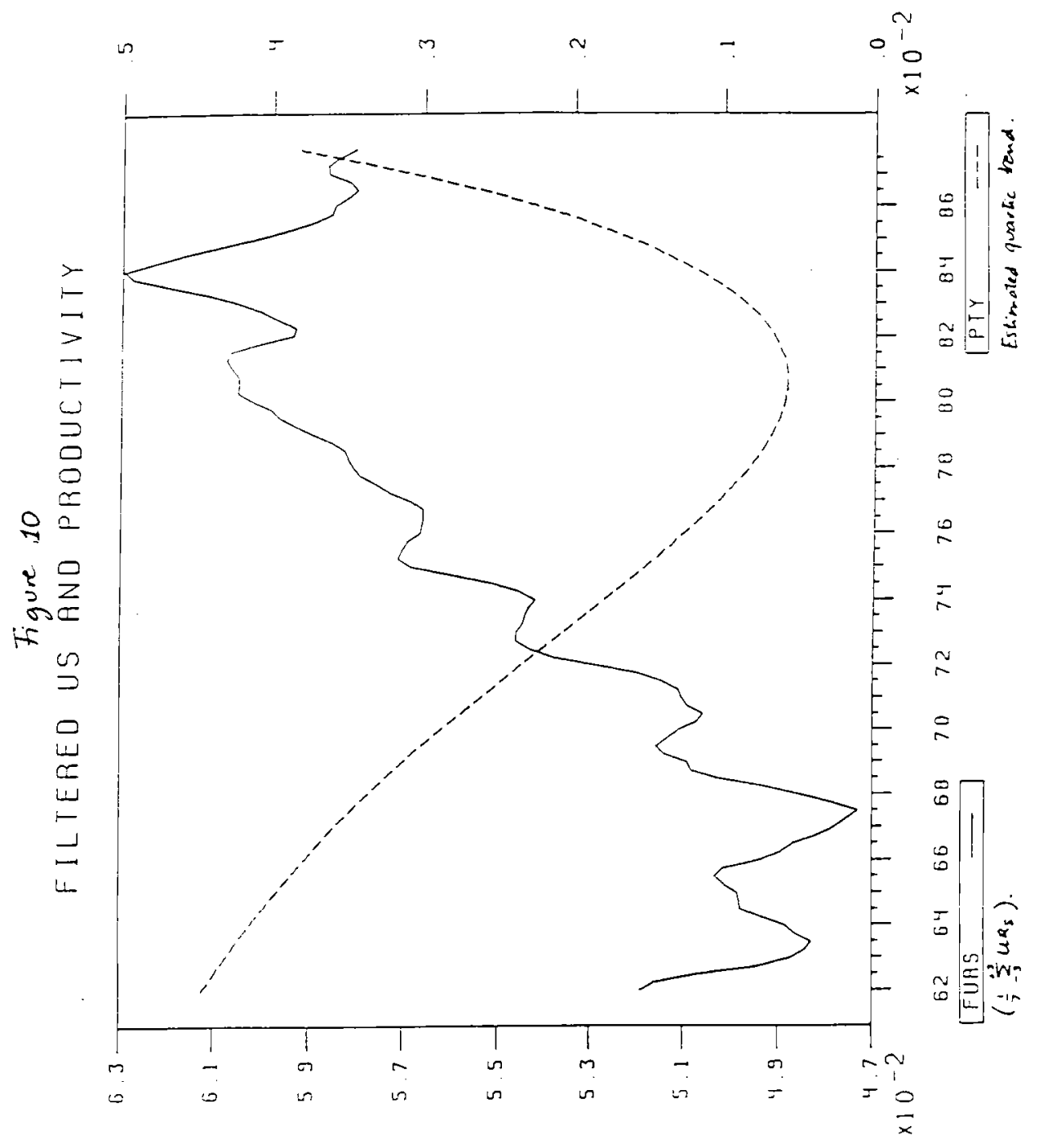


Our expectations were that Ur would have a strong negative impact on wage or price inflation, Urf would have a weaker negative impact and Urs or Urt would have little or no impact. As shown in table 6 , the results from the wage equation are dramatically at variance with these priors. The typical pattern of results is that Ur has indeed a significant, negative effect on wages. But Urs has a larger and more significant negative effect. Urt in contrast has a large and positive effect. When Ur and Ur are entered as a sum, as both appear to reflect the effects of changes in reallocation, they still come in as significantly negative, with an effect stronger than Ur. In this case, Urf enters negatively. The results are robust to constraining the coefficient on actual and expected inflation to be respectively zero and one (these results are not reported).

One tentative explanation for these results is that $\mathrm{Ur}_{\mathrm{s}}$ actually proxies for -left out-productivity growth, which clearly belongs in the wage equation. That changes in the rate of productivity growth would be zelated to the intensiveness and effectiveness of reallocation is a priori plausible. Indeed $\mathrm{Ur}_{s}$ and labor productivity growth follow roughly opposite symmetrical movements over the sample period. This is made clear in Figure 10 which plots (a 7 -quarter centered moving average of) Ur against a quartic trend fitted to labor productivity growth in the private non-farm sector. We therefore include the fitted quartic trend in the wage regression; the results of a regression which takes wage inflation minus expected price inflation minus fitted productivity as the left hand side variable are given in the second part of table 6 . The results are roughly the same as before. This remains true when fitted productivity growth is entered as a right hand side variable, with a free coefficient (these results are not reported). Thus, either our proxy for productivity growth is poor, or Urs truly has a large effect on wage inflation, and our formalization leaves out some important aspect of wage setting. 
That the problem may be one of controlling for productivity growth is suggested by estimation of the reduced form price equation, which does not suffer from the unobservability of productivity growth to the same extent. There, the results are very much as expected. Ur $r_{c}$ is more strongly significant than Ur itself and the other components, including Ur, are insignificant. Taking those results at face value, this suggests that the observed right shifts in the expectations adjusted Phillips curve the increase in the "natural rate" or in the "NAIRU", documented in a large number of Brookings Papers through the $70^{\prime} \mathrm{s}$ - and in the Beveridge curve were largely due to an increase in $\mathrm{Ur}_{s}$. The recent decline in $\mathrm{Ur}_{s}$ suggests, symetricaliy, a decline in the "natural" rate. These conclusions are obviously tentative, given the results of estimation of the wage equation. Once more, these results imply a clear research agenda, one we shall pursue in the future.

\section{Conclusions}

In this paper we have presented a picture of the labor market, one with large flows of jobs and workers, and matching. We have developed a consistent approach to the interaction among those flows and the stocks of unemployed workers and vacant jobs, and to the determination of wages. At each point, we have confronted the assumptions and the implications of our approach to the data. We are encouraged by our first pass at the data. We see the estimation of the matching function as a success, and our decomposition of movements in unemployment and vacancies as highly plausible. There is clearly a lot more work to be done, and we apologize if the paper sounds too much like a research agenda; one which is indeed our research agenda for the near future. 


\section{References}

Abowd, John and Arnold Zellner, "Estimating Gross Labor-Force Flows", Journal of Business and Economic Statistics, July 1985, 3-3, 254-283

Abraham, Katharine, "Structural/Frictional vs Deficient Demand: Some New Evidence", American Economic Review, September 1983, 83-4, 708-724

Abraham, Katharine, "Help Wanted Advertising, Job Vacancies and Unemployment", Brookings Papers on Economic Activity, 1987-1, 207-248

Abraham, Katharine and Lawrence Katz, "Cyclical Unemployment: Sectoral Shifts or Aggregate Disturbances?", Journal of Political Economy, June 1986, 94-3, part 1, 507 522

Abraham, Katharine and James Medoff, "Unemployment, Unsatisfied Demand for Labor and Compensation Growth, 1956-1980", in Martin Baily ed., "Workers, Jobs and Inflation", Brookings 1982

Akerlof, George, Andrew Rose and Janet Yellen, "Job Switching and Job Satisfaction in the US Labor Market". Brookings Papers on Economic Activity, 1988-2, 495-582

Baily, Martin and James Tobin, "Macroeconomic Effects of Selective Public Employment and Wage Subsidies", Brookings Papers on Economic Activity, 1977-2, $511-541$ 1989

Blanchard, Olivier Jean, "Two Tools for Analyzing Unemployment", mimeo MIT, June

Blanchard, Olivier Jean and Peter Diamond, "The Beveridge Curve," Brookings Papers on Economic Activity, $1989-1,1-75$

Blanchard, Olivier Jean and Peter Diamond, "Long Term Unemployment and Wage Determination", mimeo MIT, July 1989

Brownlie, A. and P. Hampton, "An Econometric Study of Wage Determination in New Zealand", International Economic Review, 8-3, October 1967, 327-334

Budd, Alan, Paul Levine and Peter Smith, "Unemployment, Vacancies and the Long Term Unemployed", Economic Journal, December 1988, 1071-1091

Bulow, Jeremy and Lawrence Sumners, "A Theory of Dual Labor Markets with Application. to Industrial Policy, Discrimination and Keynesian Unemployment", Journal of Labor Economics, June $1986,4,376-414$

Cohen, Malcolm and Robert Solow, "The Behavior of Help Wanted Advertising", Review of Economics and Statistics, February 1967, 49, 108-110

Davis, Steve and John Haltiwanger, "Gross Job Creation, Gross Job Destruction, and Intrasectoral Labor Reallocation", mimeo 1989

Diamond, Peter, "Aggregate Demand Management in Search Equilibrium", Journal of Political Economy, October 1982, 881-894 
Dow, J.C.R. and L.A. Dicks-Mireaux, "The Excess Demand for Labor: A Study of the Conditions in Great Britain, 1946-1956", Oxford Economic Papers, 10, 1958, 1-33

Gordon, Robert, $J .$, "Inflation, Flexible Exchange Races, and the Natural Rate of Unemployment", in "Workers, Jobs and Inflation", M. Baily ed, Brookings, 1982, 89-158

Hansen, Bent, "Excess Demand, Unemployment, Vacancies and Wages", Quarterly Journal of Economics, Eebruary 1970, 84, 1-23

Holt, Charles, and Martin David, "The Concept of Job Vacancies in a Dynamic Theory of the Labor Market", in "Measurement and Interpretation of Job Vacancies", NBER, New York, Columbia University Press, 1966, 73-127

Jackman, Richard, Richard Layard and Christopher Pissarides, "On Vacancies", Center for Labour Economics, LSE Discussion Paper 165 (revised), Augus 1984

Jackman, Richard and Richard Layard, "Does Long Term Unemployment Reduce a Person's Chance of a Job? A Time Series Test", CLE LSE working paper 883R, March 1988

Katz, Lawrence, "Layoffs, Recalls and the Duration of Unemployment", NBER WP 1825, January 1986

Katz, Lawrence and Bruce Meyer, "Unemployment Insurance, Recall Expectations and Unemployment", mimeo September 1987

Layard, Richard and Sceve Nickell, "The Performance of the British Labour Market" LSE, 1986

Lilien, David, "Sectoral Shifts and Cyclical Unemployment", Journal of Political Economy, 1982, 90,777-793

Myers, John, and Daniel Creamer, "Measuring Job Vacancies; A Feasibilicy Study in the Rochester, N.Y. Area", Conference Board Studies in Business Economics, 97,1967

Pissarides, Christopher, "Short Run Equilibriun Dynamics of Unemployment, Vacancies and Real Wages", American Economic Review, 75-4, September 1985, 676-690

Pissarides, Christopher, "Unemployment and Vacancies in Britain", Economic Policy, October $1986,3,499-560$

Pissarides, Christopher, "Search, Wage Bargains and Cycles", Review of Economic Studies, $1987,54,473-483$

Samuelson, Paul and Robert Solow, "Analytical Aspects of Anti-Inflation Policy," American Economic Review (Papers and Proceedings) 50, no. 2 (May 1960), $177-194$

Schultze, Charles, "Has the Phillips Curve Shifted ? Some Additional Evidence", Brookings Papers on Economic Activity, 1971-1, 452-467 
Solow, Robert, "The Nature and Sources of Unemployment in the United States". Wicksel1 Lectures, 1964 Stockholm: Almquist and Wickse11, 1964

Solow, Robert, Price Expectations and the Behavior of the Price Level (University of Manchester Lectures), Manchester: Manchester University Press, 1969

Solow, Robert, "Down the Phillips Curve with Gun and Camera", in Inflation, Irade and Taxes: Essays in Honor of Alice Bourneuf, Columbus: Ohio State University Press, 1976 